\title{
Designing a capacitated multi-configuration logistics network under disturbances and parameter uncertainty: a real-world case of a drug supply chain
}

\author{
Davood Shishebori ${ }^{1} \cdot$ Abolghasem Yousefi Babadi $^{2}$
}

Received: 27 January 2017/ Accepted: 13 May 2017/Published online: 23 May 2017

(C) The Author(s) 2017. This article is an open access publication

\begin{abstract}
This study investigates the reliable multi-configuration capacitated logistics network design problem (RMCLNDP) under system disturbances, which relates to locating facilities, establishing transportation links, and also allocating their limited capacities to the customers conducive to provide their demand on the minimum expected total cost (including locating costs, link constructing costs, and also expected costs in normal and disturbance conditions). In addition, two types of risks are considered; (I) uncertain environment, (II) system disturbances. A two-level mathematical model is proposed for formulating of the mentioned problem. Also, because of the uncertain parameters of the model, an efficacious possibilistic robust optimization approach is utilized. To evaluate the model, a drug supply chain design $(\mathrm{SCN})$ is studied. Finally, an extensive sensitivity analysis was done on the critical parameters. The obtained results show that the efficiency of the proposed approach is suitable and is worthwhile for analyzing the real practical problems.
\end{abstract}

Keywords Multi-product - Multi-type transportation links · Multi-vehicles · Multi-configuration · Capacitated logistic network design (LND) - Disturbances - Two-stage decomposing heuristic $\cdot$ LP relaxation $\cdot$ Medical service (drug)

Davood Shishebori

Shishebori@yazd.ac.ir

1 Department of Industrial Engineering, Yazd University, Pajoohesh Square, Yazd 89195741, Iran

2 School of Industrial and Systems Engineering, University of Tehran, Tehran, Iran

\section{Introduction}

Due to the competitive world of manufacturing in the twenty-first century, nowadays, the supply chain network design (SCND) issue and its related topics have a special importance in the optimization research areas, because this issue is one of the key factors that may arouse a key role in the reduction of various costs (such as costs of location, construction, operation, production, transportation) as well as increase the efficiency of production and service systems.

The past studies demonstrate that several mathematical programming models have been developed to unravel a variegation of SCND problems. Some reviews have mentioned their models, algorithms and applications (Meixell and Gargeya 2005; Daskin et al. 2005; Hatefi et al. 2015; Cardona-Valdes et al. 2014).

Since the SCND is known to be a long-term strategic decision problem, considering various practical factors can help get more efficient solutions to the problem under study. Risk is known to be a key factor in this context. Recently, this topic in the SCND has been an incentive context for most corporations in the trade growth world.

On one view, there are two broad classes of risks that influence the design of the supply chain (SC): (I) the risk emanating from the adversities in moderating demand and supply and (II) the risk emanating from a fulmination of disruptions to usual processes, which includes the themes depending on indigenous catastrophes, stay-in strikes, economical interruptions, and terroristic acts (Kleindorfer and Saad 2005; Hatefi et al. 2015).

The first class of risks is studied in the major frame of the SC background. The existent uncertainties in the demand, lead times, transportation expenditures, and the quality and quantity of returning commodities refer to this 
class of risks. The stochastic programing and robust optimization (RO) are the most efficient tools used for considering the uncertain parameters (Birge and Louveaux 2011).

Also, the second category of risks is considered in some studies in the SC literature. Generally, this kind of risk is known as system disturbances. In fact, SCs are subject to several possible provenances of disturbances, where disturbances are unanticipated and unplanned incidents that interrupt the ordinary flow of materials and products through an SC. The disturbance at one part of an SC may cause a substantial influence over the whole chain. SCs are subject to several possible provenances of disturbances. Some of them are external sources (e.g., natural disaster, terrorist attack, power outages, and supplier discontinuities), while others are internal sources (e.g., industrial accidents, labor strikes).

Since most of the supply chain infrastructures are generally widespread and their constructions are expensive and time consuming, it will be very costly and difficult to rectify the design. Accordingly, it is most worthy to scheme an SC that achieves efficiency and continuity under all kinds of risks from the beginning. In comparison to the existing literature, the contribution of this paper is as follows:

- Investigation of multi-configuration (including multiproduct, multi-type link, and multi-vehicle) structure in the network designing of the capacitated SC problem.

- Study of uncertain environment (containing uncertainty of transportation costs and demands) in the network designing of the capacitated SC problem.

- Investigation of system disturbances, which subtends potential interruptions in facilities, the network transportation links, distribution centers, and vehicles.

- Use of the production-distribution system which is a "customer to server" system.

- Applying the formulation in a real practical case study from the medical service (drug) supply chain.

These contributions have been somewhat indicated in the last row of Table 1 in terms of the formulation's characteristics and the background taxonomy. In this study, the mentioned problem is named robust and reliable capacitated multi-configuration supply chain network design problem (RR/CMc/SCNDP). To the best of our knowledge, such a study has not been conducted till now.

The rest of this article is structured as follows. Section "Literature Review" purveys a relatively comprehensive background in four main streams. The problem definitions and the proposed mathematical programming model are proposed in "Problem definition and formulation" section. Then, in "Mathematical modeling" section, the reliable counterpart of the proposed model in "Problem definition and formulation" section is considered. In "Solution approach", an efficacious solution approach is proposed. A real practical case study is represented and analyzed in "Real life case study" section. In "Sensitivity analysis" section, a comprehensive sensitivity analysis at five subsections is represented. Finally, conclusions and some future guidelines are discussed.

\section{Literature review}

In the SCND and logistics literature, system disturbances are known to be a special issue of supply uncertainty. These disturbances are introduced as random incidents that lead some elements of the SC to lay off functioning, either partially or completely, for a (generally random) value of time. Several robust strategies and approaches have been proposed to relieve the efficacies of SC interruptions and improve the efficiency of SC and its logistics at disturbance conditions. For more study, the scholar is referred to the review by Snyder et al. $(2006,2016)$.

Conductive to place our contribution in the straight panorama, four primary streams of the background may be reviewed that can be of penchant for contrast: (I) the SCND subject to system disturbances, (II) the capacitated SCND, (III) the SCND subject to parameter uncertainty, (IV) the multi-configuration SCND.

It is noted that in this study, the system disturbances are defined as facility disturbances, transportation link disturbances, and transportation vehicle disturbances.

\section{SCND with system disturbances}

The literature system (including facility and link) disturbances on SCND can be briefly reviewed as follows. Peng et al. (2011) considered the efficacy of studying unreliability in LND problems in the presence of facility interruptions as several scenarios. They demonstrated that utilizing a reliable LND is frequently conceivable with insignificant increases in whole location and allocation expenditures. Moreover, Jabbarzadeh et al. (2012) reformulated a mixed-integer non-linear program (MINLP) for an SC design quandary in which distribution centers can have complete and partial interruptions. Aydin and Murat (2013) studied the capacitated reliable facility location (CRFL) quandary in the presences of facility interruptions as scenarios. They proposed an efficient algorithm as hybridization of particle swarm intelligence (PSO) and sample average approximation methods. (Shishebori et al. 2013), and Shishebori and Jabalameli (2013a, b) studied facility disturbances as a constraint for the maximum permissible disturbance expenditure of the system. They proposed an MINLP formulation and considered it by a 


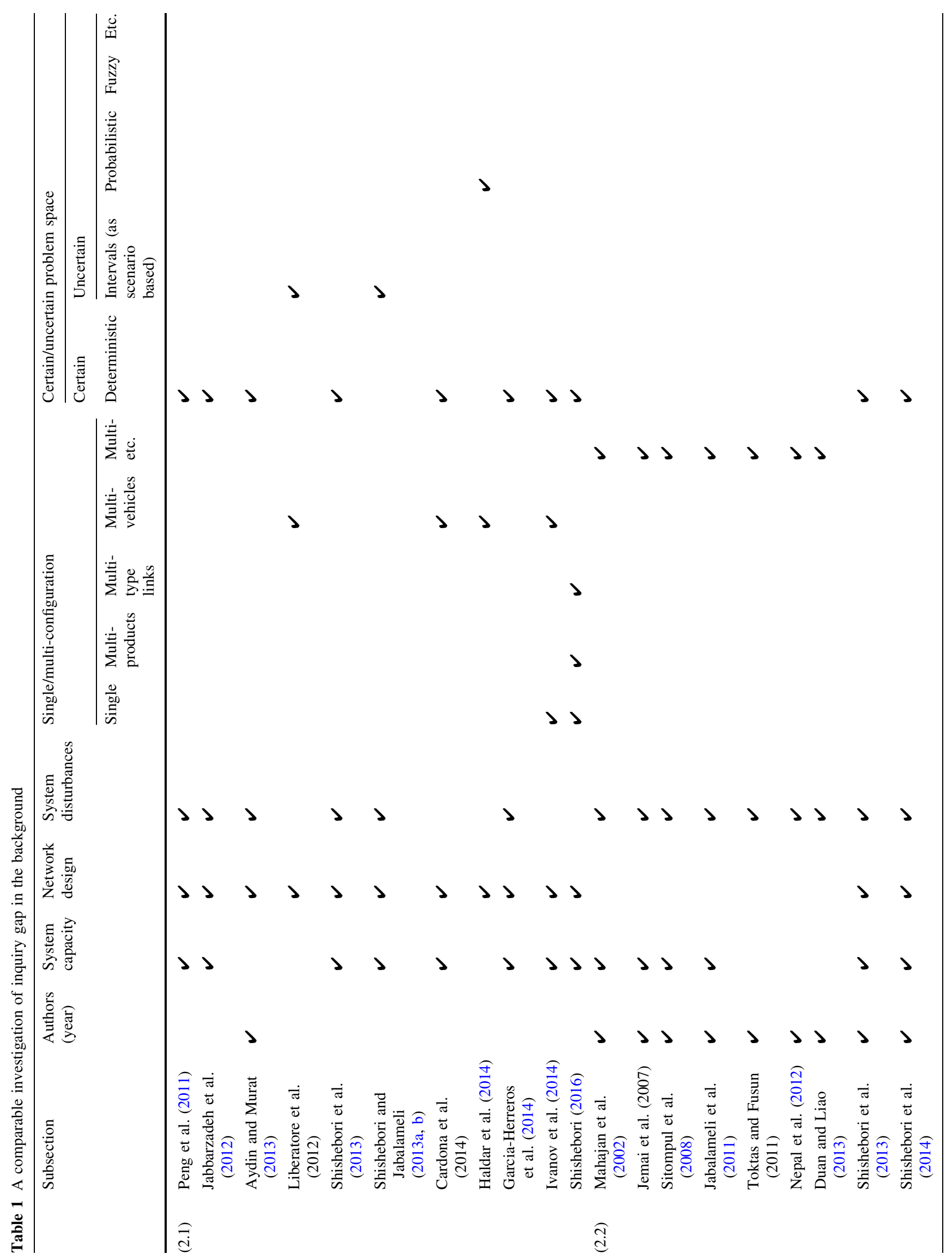




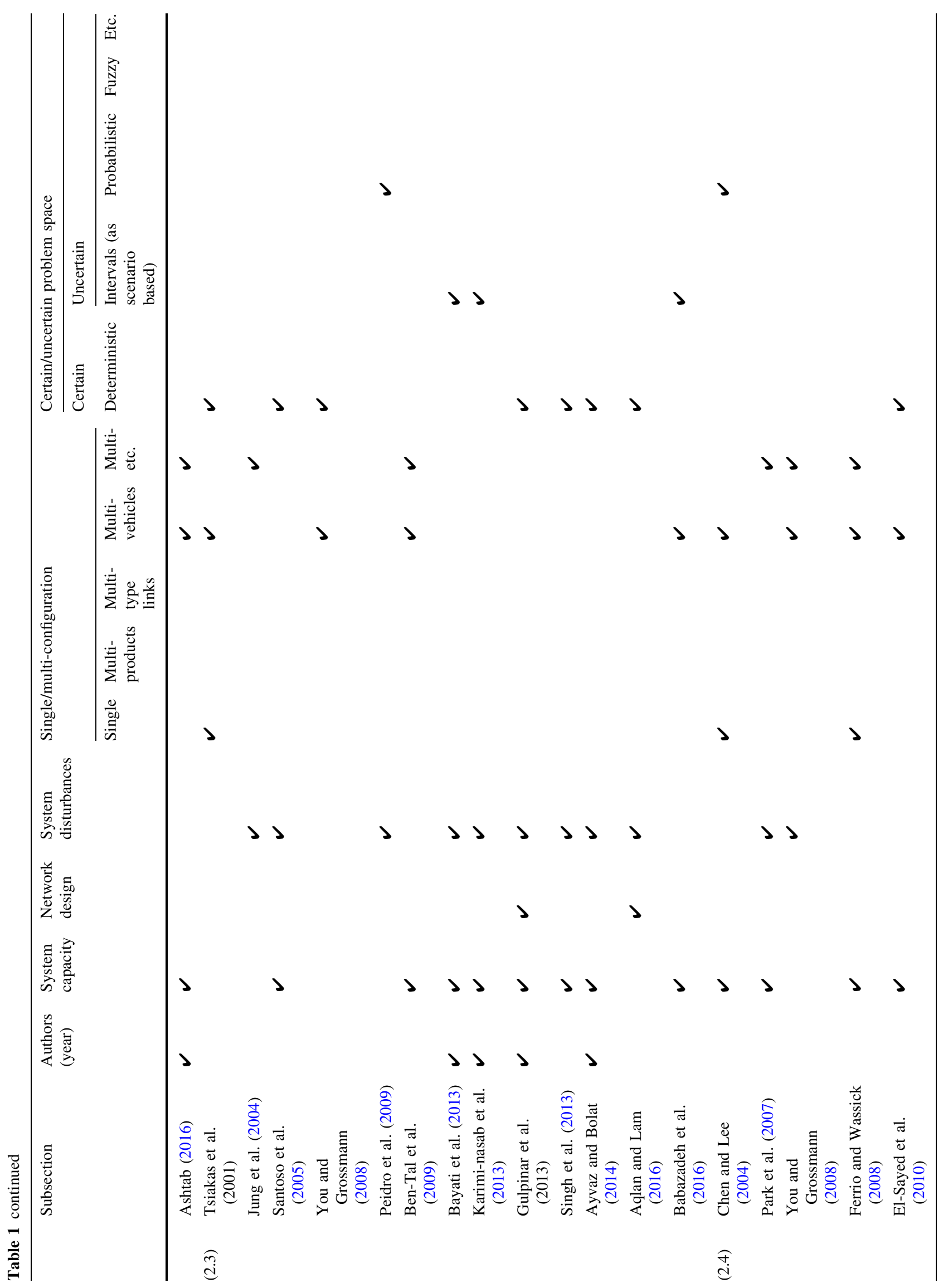




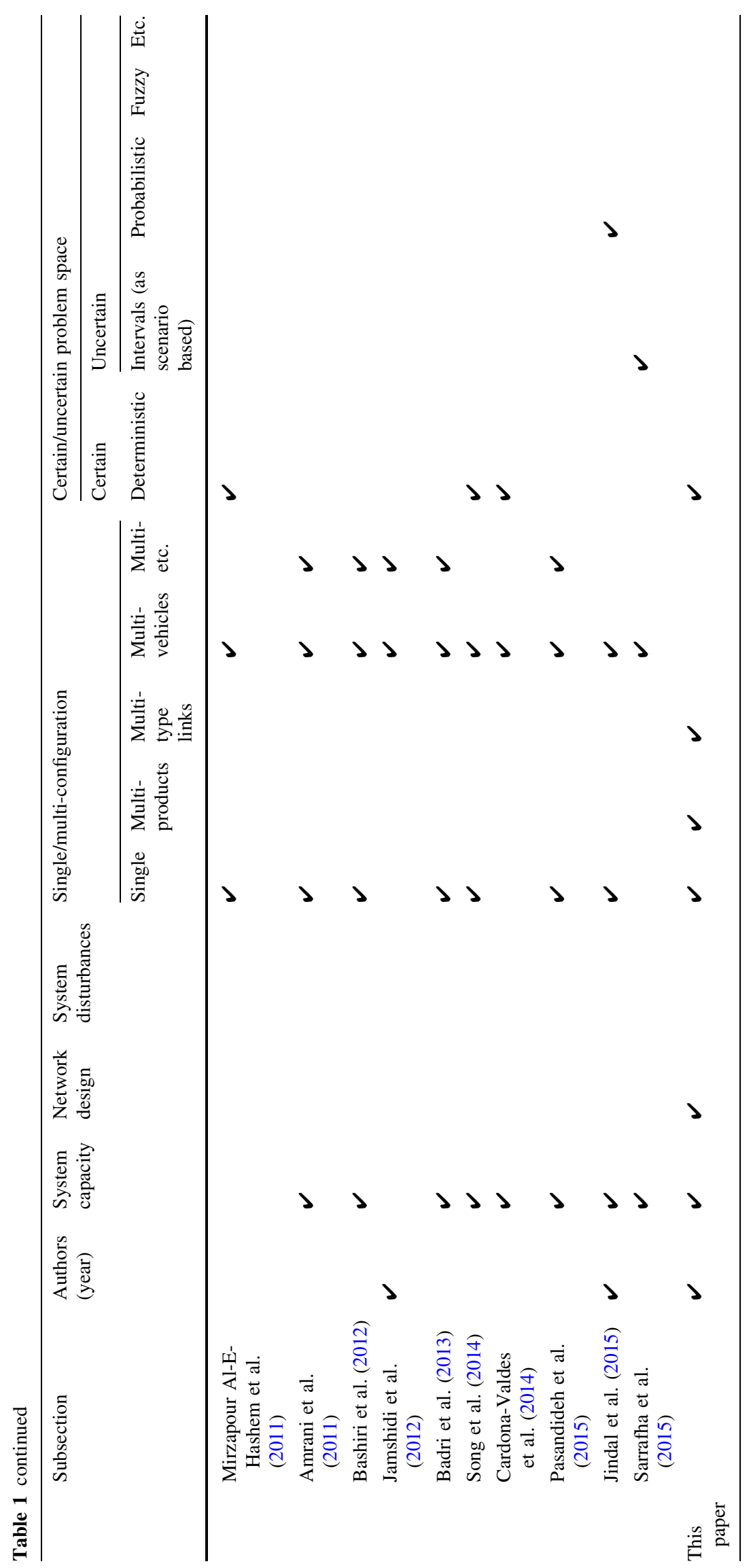


case study. Garcia-Herreros et al. (2014) developed a twostage stochastic program to plan resilient SCs in which the distribution centers are subject to the risk of interruptions at candidacy locations. Ivanov et al. (2014) formulated a multi-commodity and multi-period distribution (re)planning quandary for a multi-phase centralized network with frame dynamics investigations held forth. Their approach permits investigating several implementation scenarios and expanding motions on (re)planning in the case of perturbations. Shishebori (2016) studied the reliable multi-product multi-vehicle multi-type link logistics network design problem (RMLNDP) regarding the system disturbances. They modeled the problem as an MIP model to provide a reliable sustainable multi-configuration logistic network system. Yousefi-Babadi et al. (2017) proposed a multiobjectives mixed-integer non-linear programming (MINLP) model for a petrochemical supply chain under uncertainty environments, namely disruption risks and less knowledge of parameters. In their model, two efficient queuing systems are applied in nylon plastic manufacturing and recycling centers, in which a Jackson network is also used. The aims are to minimize the average tardiness to deliver products, total cost and transportation cost. Finally, they applied the Lagrangian relaxation based on a subgradient approach to solve the proposed model.

\section{Capacitated SCND}

Capacity is known as another significant factor that plays a critical role in SCND. Several studies were done regarding SC limited capacity. Mahajan et al. (2002) dissected an SC consisting of uncapacitated/capacitated suppliers for diffusing two autonomous commodities via multiple retailers and studied the problem by means of the game theory. Jemai and Karaesmen (2007) considered a two-phase SC consisting of a retailer and a capacitated supplier in the structure of a Nash game. Sitompul et al. (2008) modeled the safety holding assignment quandary for an $n$-phase capacitated consecutive SC and suggested a solution scheme with the objective of maintaining the needed entire service surface at the lowest expenditure. Jabalameli et al. (2011) formulated a budgetconstrained dynamic (multi-period) uncapacitated facility location-network design problem (DUFLNDP). Their problem dealt with the determination of the optimal locations of facilities and the design of the underlying network simultaneously. Toktas-Palut and Fusun (2011) formulated an M/M/ 1 make-to-stock queuing network in a decentralized twophase SC including a manufacturer with limited production capacity and multiple autonomous suppliers. Nepal et al. (2012) indicated an investigation of a three-stage SC studying capacity circumscription and step changes in SC utilization rate according to life cycle demand stages. Duan and Liao (2013) represented a simulation -based optimization frame conducive to specify the near-optimal SC replenishment strategies in the presence of different demands and handle strategies for a capacitated SC. They examined a capacitated single distributor-multi-retailer SC discipline in detail. Shishebori (2014) studied facility disturbances via a constraint on the maximum permissive interruption expenditure of the system in the context of an FLNDP with interruptions. They proposed an MINLP model for the quandary and illustrated it by a case study. Shishebori et al. (2014) considered a similar FLNDP and proposed an LPbased heuristic to solve it. Ashtab (2016) studied a threeechelon capacitated SCND with customer zones, distribution centers (DCs), and suppliers. The proposed formulation takes into account the operative expenditures of an established DC due to its practical activity surface instead of the presumption that an established DC functions at the uttermost acumen. Some other related paper can be found in Taleizadeh et al. (2008, 2009, 2010a, b, 2011, 2012, 2013a, b, 2014), Taleizadeh and Pentico (2013), Taleizadeh (2014), Taleizadeh and Nematollahi (2014) and Taleizadeh and Pentico (2014).

\section{SCND with parameter uncertainty}

In the background, different formulations for SC designing in the presence of uncertainty are described. Utmost are due to hybrid approaches (due to the accretion of simulation and analytic formulations), simulation approaches, or analytic approaches (i.e., stochastic formulations) (Peidro et al. 2009). In these approaches, the SC uncertainties are presented with probability distributions which are commonly forecasted from historical data. Howbeit, whenever statistical data are not reliable, or are not even existent, formulations due to the designation of these contingency distributions might not be the best selection (Wang and Shu 2005). In this setting, the possibility theory and the fuzzy set theory could purvey a superseded approach to consider SC uncertainties. Tsiakis et al. (2001) dealt with a multistage, multi-product SC in the presence of demand uncertainty due to scenario type. Jung et al. (2004) studied the application of deterministic scheduling and planning formulations which integrate safety holding surfaces as a means of taking into account the demand uncertainties in the chemical process industry SC. Santoso et al. (2005) dealt with an uncertain programming approach and dissolution methodology for unraveling SCND quandaries of a real practical scale under system uncertainty. You and Grossmann (2008) proposed an optimizing formulation to plan a multi-stage SC and the dependent inventory systems regarding the demand uncertainty in the chemical mystery. Peidro et al. (2009) modeled a fuzzy MIP model for SC planning which deals with the process, demand, and supply uncertainties in the presence of ill-known data. Moreover, Ben-Tal et al. (2009) modeled the multi-term inventory 
control problem conducive to optimize the expected cost that includes the costs of flows, transfer links, capacities, and middle-stage facility locations. Singh et al. (2013) formulated a two-phase stochastic programming formulation for capacitated network design of an SC with flexible demands. Bayati et al. (2013) proposed an optimal pricing and marketing planning where the primary objective function is to maximize the total profit. Their mathematical model was considered with different input parameters and coefficients in the uncertain state. Also, they provided a suitable approach that calculates a lower and upper bounds for the objective function of the model. Karimi-Nasab et al. (2013) proposed a multi-objective approach to determine the distribution policy for a wholesaler. In their approach, the wholesaler distributes supplementary nutrition to a set of local distribution centers positioned around the wholesaler, geographically. Their approach optimizes the selling price, carrying cost, batch size and services level of multiitems for each local distribution center in every planning period. Ayvaz and Bolat (2014) formulated a general twophase probabilistic programming formulation to tackle uncertainties in reverse logistics network design. Aqlan and Lam (2016) presented a methodology and a software utility for SC optimization in the presence of uncertainty and risk. Their methodology involves solving a deterministic multiobjective model as well as using a simulation formulation to illustrate the stochastic elements of the SC. The two formulations argue optimizing the lead time, profit, and risk reduction via opting an integration of extenuation policies and allocating inventory and orders. Babazadeh et al. (2016) modeled a multiple objective stochastic programming formulation for designing a second-generation biodiesel SC network regarding the risk investigating total cost and environmental impact minimization. They presented a new formulation of stochastic programming method which is able to minimize the total mean and risk values of stochastic -based uncertain problems. Keyvanshokooh et al. (2016) developed a novel hybrid robuststochastic programming (HRSP) approach to simultaneously model two different types of uncertainties by including stochastic scenarios for transportation costs and polyhedral uncertainty sets for demands and returns in the closed-loop supply chain network (CLSCN) design problem. Transportation cost scenarios are generated using a sampling method and scenario reduction is applied to consolidate them.

\section{SCND with multi-configuration}

Considering several possible aspects of the proposed problem can help to find more practical solutions. This can help decision makers to have several alternatives for the proposed SCND and logistics. The several possible aspects can include multi-product, multi-type link, and multi-vehicle. In this paper, all of them are named (called) multiconfiguration.

Several studies were done at the SCND and logistics with multi-configuration structure. Chen and Lee (2004) proposed a multi-period multi-product multi-stage formulation with multi-incompatible objectives of a multiple stage SCN as an MINLP, where fuzzy sets were investigated to explain the uncertainties contained in product prices and market demands. Park et al. (2007) developed a multi-product multi-period SC formulation, subtending factory, supplier, and distribution region to optimize the total expenditure and represented a genetic algorithm (GA) to unravel the problem. You and Grossmann (2008) proposed the optimization of a multi-echelon bi-criteria SC under demand uncertainty with the objectives of minimizing the expected lead time and maximizing the net present value. Ferrio and Wassick (2008) proposed an MILP model for chemical multi-product supply network, containing production centers, an arbitrary number of DCs, and customers. The proposed model was applied for optimizing and redesigning the network. Also, El-Sayed et al. (2010) considered a three-echelon forward-reverse multi-period logistics network design in the reverse direction in the presence of deterministic customer demand and demand uncertainty in the forward direction subject to maximizing the total expected profits. Mirzapour Al-E-Hashem et al. (2011) modeled a multi-product, multi-site multi-period, three stage SC in the presence of uncertainties of demand fluctuations and cost parameters. Amrani et al. (2011) formulated an MIP model for a multiple product production-distribution network such that the considered network has the property of alternative facility configuration. Bashiri et al. (2012) studied a multi-echelon network considering several time resolution decisions and tactical and strategic planning and developed a new multi-product mathematical formulation. Jamshidi et al. (2012) modeled a bi-objective multiechelon SCN design problem in which multifold transportation selections at each level of the SC are considered with a capacity constraint and several costs. Keyvanshokooh et al. (2013) addressed the problem of designing and planning a multi-period, multi-commodity and capacitated integrated forward/reverse logistics network/closed-loop supply chain network. Badri et al. (2013) proposed a new multiple commodity SCND for making strategic and tactical decisions. Maximizing the total net income thorough the time is the obvious objective function of the proposed problem. Moreover, Sarrafha et al. (2015) studied an SCND containing factories, suppliers, retailers, and DCs. They proposed a multi-period structure such that a flow-shop scheduling formulation in the manufacturing portion of the SC and 
also the shortage in the framework of backorder are combined in each period. Jindal et al. (2015) studied the optimization of a multi-echelon, multi-time multi-product capacitated closed-loop SCNDP in an uncertain circumference. The uncertainties were relevant to several parameters such as return volume, product demand, inventory cost, transportation cost, and processing cost. Fattahi et al. (2015) developed different mixed-integer linear programming (MILP) models for designing centralized and decentralized supply chains using two-stage stochastic programming. They investigated a multiple period replenishment problem based on $(s, S)$ policy for these supply chain models.

\section{Research gap and our contribution}

Some of the previous works have studied the SCND and logistics with facility disturbances and regarding link disturbances separately. Moreover, most of them did not consider the capacity (including facilities, vehicles, and transportation links). However, in some manufacturing industries, there are some capacitated SC and logistics systems in which a variety of disturbances (failures) may occur. The most obvious examples are SC of different spare parts, food product manufacturing, petrochemicals, etc.

In contrast to previous works in this constitution, this paper investigates the problem of robust and reliable designing of a capacitated SC network (SCN), which consists of suppliers, DCs, transportation vehicles and demand sites as well as some transportation links. They are potential and it should be decided that which potential sites and links should be built. Moreover, the $\mathrm{SCN}$ has a multi-configuration structure; i.e., there are the multi-product, multi-type link, and multi-vehicle states in the considered SCN. Also, two types of risks are considered: (I) uncertain environment, (II) system disturbances. It is obvious that modifying this SCN and its related logistics will be very difficult and costly. Therefore, it is important to design a reliable and robust SCN that reaches suitable stability and performance under several kinds of risks from the beginning. A twolevel mathematical model is proposed for modeling the mentioned problem. Also, because of uncertain parameters of the model, an efficient robust optimization approach is applied.

In other words, the following questions are answered in this paper:

1. Which facility should be located in which site?

2. Which links between which facilities should be established?

3. Which kind of link quality should be established?
4. Which vehicle between which facilities should be established?

5. How many products should be transported between facilities?

6. Which vehicles transport these products?

\section{Problem definition and formulation}

The working conditions of the RR/CMc/SCNDP can be described as follows. Let $G_{\mathrm{S}}, G_{\mathrm{T}}$, and $G_{\mathrm{D}}$ signify the sets of supply, transportation, and demand sites, respectively. Also, the $G_{0}$ is defined as the set of all supply and transportation sites $\left(G_{0}=G_{\mathrm{S}} \cup G_{\mathrm{T}}\right)$, the sites for which close/ open decisions are necessary. The set $G_{0}$ can be called "facilities". All of the facilities and transportation links are capacitated and have a maximum level (capacity) in order to service to the demand sites. Suppose $S$ be the set of scenarios, each of which distinguishes a set of facilities, transportation links, and transportation vehicles that are simultaneously disrupted. Suppose $s=0$ as the nominal scenario in which no disturbances happen. The set $P$ illustrates several types of products that should be produced and transported to the demand sites. The set $L$ presents different kinds of transportation links. For example, for each link, it is assumed that three various quality levels (i.e., $|L|=3$ ) may be considered; each of which is defined as follows: the paved road with the standard quality (type 1), the paved road with low quality (type 2), and the dirt road (type 3 ). As seen, if a link with type 1 quality is constructed, its establishment cost will be more than the other types, while its capacity is more and its transportation cost is lower than the other quality types of transportation links. Here, links (roads) with three quality types are defined; however, several quality types can be defined for the problem. Also, the set $V$ shows several types of transportation vehicles. The best type of the vehicle has the highest cost of investment, but the lowest cost of transportation and the worst type is vice versa. Several vehicles, which can be used and categorized as different types of vehicles are airplane, helicopter, train, refrigerated pickups/truck, etc. These vehicles are selected with regard to the required investment cost, the necessity of the product (e.g., drug or medical service), probability of system risk, or other practical factors.

To avoid infeasible situations, a penalty fee is ordained for the demands of sites that cannot feasibly be met. It can be denoted that these demands are fulfilled from some outside suppliers as emergency facilities, but with high transportation costs. Also, it can be interpreted that the demand of a site can be not to provide if the cost of providing the demand of the site is greater than the penalty of 
it. In this paper, this contingency is considered by supposing that $N_{\mathrm{S}}$ subtends an "emergency facility" that does not have any establishment cost and is never laid on risky situations; also, it has infinite capacity. Obviously, it is ever more open in the optimum solution and does not have any risky situations. For each transportation link, from the emergency facility to other sites, the unit transportation cost is equal to the unmet demand penalty fee.

The sets and parameters of the problem are as follows:

\section{Sets}

$G$ : set of sites $\left(G=G_{\mathrm{S}} \cup G_{\mathrm{T}} \cup G_{\mathrm{D}}\right)$,

$P$ : set of products $(p=1, \ldots, N P)$,

$L$ : set of several quality types of transportation links $(l=1, \ldots, N L)$,

$V$ : set of several types of transportation vehicles $(v=1$, ..., $N V$ ),

$A$ : set of potential transportation links $(i=1, \ldots, N I$ and $j=1, \ldots, N J$,

$S$ : set of scenarios. In all possible scenarios, each scenario illustrates the facilities and also link disturbances $(s=1, \ldots, N S)$.

Parameters

$f_{j}=$ fixed cost of locating the facility $j \in G_{0}$,

$\pi^{s}=$ probability of happening of unreliable scenario $s \in$ $S ; \pi^{s} \in[0,1]$,

$c_{i j}^{l}=$ construction cost of link $(i, j) \in A$ with quality type $l(l \in L)$,

$t_{i j}^{p l v}=$ unit transportation cost of commodity $p(p \in P)$ on link $(i, j) \in A$ with quality type $l(l \in L)$ by vehicle $v(v \in$ V),

$\gamma_{i j}^{v}=$ investment cost of vehicle $v(v \in V)$ at link $(i, j) \in$ A,

$\lambda_{i j}^{v}=$ capacity of vehicle $v(v \in V)$ at link $(i, j) \in$ $A$ (according to kilogram criteria),

$\Gamma_{j}=$ capacity of facility at site $j \in N_{S}$ (according to processing time criteria),

$\varphi_{j}^{p}=$ processing time of commodity $p(p \in P)$ at site $j \in$

$G_{\mathrm{S}}$,

$\Theta_{j}^{p}=$ capacity of facility at site $j \in N_{T}$ (according to kilogram criteria),

$\Pi_{i j}^{l}=$ capacity of link $(i, j) \in A$ with quality type $l(l \in$ $L)$ (according to kilogram criteria),

$\psi^{p}=$ weight of product $p(p \in P)$,

$U_{i j}^{\max }=$ maximum number of vehicle types that may be used at link $(i, j) \in A$,

$d_{j}^{p}=$ demand of product $p(p \in P)$ at site $j,\left(j \in G_{D}\right)$,
$M=$ a large number,

$\mathrm{BC}=$ upper limit of investment budget constraint,

$P_{\mathrm{R}}=$ desired robustness level,

$\xi_{s}^{*}=$ the optimal cost of unreliable scenario $s, s \in S$,

$\Xi_{j}^{s}=$ disturbance parameter of facility at site $j,\left(j \in N_{S}\right)$

in unreliable scenario $s,(s \in S)\left(\Xi_{j}^{s} \in[0,1]\right)$,

$\mho_{i j}^{s}=$ disturbance parameter of link $(i, j) \in A$ in unreliable scenario $s,(s \in S)\left(\mho_{i j}^{s} \in[0,1]\right)$,

$\coprod_{i j}^{l v s}=$ disturbance parameter of vehicle $v(v \in V)$ at link

$(i, j) \in A$ with quality type $l(l \in L)$ in unreliable scenario $s,(s \in S)\left(\coprod_{i j}^{l v s} \in[0,1]\right)$,

$\Phi_{j}^{s}=1$ if facility at site $j \in N_{0}$ is failed in scenario $s \in S$, 0 under other conditions,

$\Omega_{i j}^{s}=1$ if link $(i, j) \in A$ is failed in scenario $s \in S, 0$ under other conditions,

$\Delta_{i j}^{l v s}=1$ if vehicle $v(v \in V)$ at link $(i, j) \in A$ with quality type $l(l \in L)$ is failed in scenario $s \in S, 0$ under other conditions.

Although $\Phi_{j}^{s}, \Omega_{i j}^{s}$, and $\Delta_{i j}^{l v s}$ are defined as binary parameters, the proposed mathematical programming model has good functionality if these parameters can be fractional, presenting partial disturbances.

Decision variables

$Z_{j}=1$ if a facility is opened at site $j \in G_{0}$, but is 0 under other conditions,

$X_{i j}^{l}=1$ if link $(i, j) \in A$ is established with quality type $l$

$(l \in L)$, but is 0 under other conditions,

$W_{i j}^{v}=1$ if vehicle $v(v \in V)$ is established at link $(i, j) \in$ $A$, but is 0 under other conditions,

$\delta_{j}=1$ if no facility is opened at site $j$ and it remains as demand site, but is 0 under other conditions

$Y_{i j}^{p l v s}=$ amount of flow of product $p(p \in P)$ on link $(i, j)$ $\in A$ with quality type $l(l \in L)$ by vehicle $v(v \in V)$ in scenario $s \in S$.

Therefore, we propose the following MIP model for the $\mathrm{RR} / \mathrm{CMc} / \mathrm{SCNDP}$.

\section{Mathematical modeling}

\section{Reliable counterpart stage 1}

The reliable counterpart stage 1 of $\mathrm{RR} / \mathrm{CMc} / \mathrm{SCNDP}$, as model (I), can be represented as follows:

Model (I): 
- Objective function:

$$
\begin{aligned}
\min \quad \mathrm{ETC}= & \sum_{j \in G_{0}} f_{j} Z_{j}+\sum_{l \in L} \sum_{(i, j) \in A} c_{i j}^{l} X_{i j}^{l}+\sum_{v \in V} \sum_{(i, j) \in A} \gamma_{i j}^{v} W_{i j}^{v} \\
& +\sum_{p \in P} \sum_{v \in V} \sum_{l \in L} \sum_{(i, j) \in A} t_{i j}^{p l v} \cdot \pi_{0} Y_{i j}^{p l v 0} .
\end{aligned}
$$

The objective Eq. (1) optimizes the expected total costs (ETC), containing constant location costs, link establishment costs, vehicle establishment costs, as well as the expected transportation costs for all possible scenarios with respect to their probabilities.

- Constraints:

$$
\begin{aligned}
& {\left[\begin{array}{c}
\sum_{j \in G_{0}} f_{j} Z_{j}+\sum_{l \in L} \sum_{(i, j) \in A} c_{i j}^{l} X_{i j}^{l}+\sum_{v \in V} \sum_{(i, j) \in A} \gamma_{i j}^{v} W_{i j}^{v} \\
+\sum_{p \in P} \sum_{v \in V} \sum_{l \in L} \sum_{(i, j) \in A} t_{i j}^{p l v} \cdot \pi_{s} Y_{i j}^{p l v s}
\end{array}\right] \leq\left(1-P_{\mathrm{R}}\right) \xi_{s}^{*}} \\
& \forall s \in S /\{0\} .
\end{aligned}
$$

Constraints (2) persuade the $P_{\mathrm{R}}$-robust criterion, entailing that the unreliable scenario costs have to be less than $100\left(1+P_{\mathrm{R}}\right) \%$ of the optimum scenario costs $\xi_{\mathrm{s}}^{*}$. If $P_{\mathrm{R}}=1$, the formulation will be equivalent to a deterministic SCNDP and the $P_{\mathrm{R}}$-robustness constraints will be inactive.

$$
\begin{aligned}
& \sum_{v \in V} \sum_{l \in L} \sum_{(j, i) \in A} Y_{i j}^{p l v s}-\sum_{v \in V} \sum_{l \in L} \sum_{(j, i) \in A} Y_{j i}^{p l v s} \\
& \quad+d_{j}^{p} \leq\left(1-\Xi_{j}^{s}\right) \Theta_{j}^{p}+M \Phi_{j}^{s}+M\left(1-z_{j}\right) \\
& \quad \forall j \in G_{0}, \quad s \in S, \quad p \in P \\
& \sum_{v \in V} \sum_{l \in L} \sum_{(j, i) \in A} Y_{j i}^{p l v s}-\sum_{v \in V} \sum_{l \in L} \sum_{(j, i) \in A} Y_{i j}^{p l v s} \leq d_{j}^{p}+M \delta_{j} \\
& \quad \forall j \in G_{0}, \quad s \in S, \quad p \in P \\
& \sum_{v \in V} \sum_{l \in L} \sum_{(j, i) \in A} Y_{j i}^{p l v s}-\sum_{v \in V} \sum_{l \in L} \sum_{(j, i) \in A} Y_{i j}^{p l v s} \geq d_{j}^{p}+M\left(1-\delta_{j}\right) \\
& \forall j \in G_{D}, \quad s \in S, \quad p \in P, \\
& \delta_{j}+\left(1-\Phi_{j}^{s}\right) z_{j}=1 \quad \forall j \in G
\end{aligned}
$$

Constraints (3)-(5) are known as the flow conservation constraints. Constraints (3) monitor the supply sites and control the supply that flows. Constraints (4)-(5) screen the demand sites and control the demand to be equal in the flow in and flow out of the site. Each supply/demand site may be employed as a transportation site and may have a logical flow out and flow in. Constraints (6) vouch that each site can be specified as either supply site or demand site; i.e., each site cannot be simultaneously known as demand site and supply site; in other words, each site can be just a demand site or supply site, but not both of them,

$\sum_{j \in G_{0}} f_{j} Z_{j}+\sum_{l \in L} \sum_{(i, j) \in A} c_{i j}^{l} X_{i j}^{l}+\sum_{v \in V} \sum_{(i, j) \in A} \gamma_{i j}^{v} W_{i j}^{v} \leq \mathrm{BC}$.

Constraint (7) represents the investment constraint.

$\sum_{p \in P} \sum_{v \in V} \sum_{l \in L} \sum_{(i, j) \in A} \varphi_{j}^{p} Y_{i j}^{p l v s} \leq\left(1-\Phi_{j}^{s}\right)\left(1-\Xi_{j}^{s}\right) \Gamma_{j} Z_{j}$
$\forall j \in G_{S}, \quad s \in S$.

Constraints (8) ensure that the summation of the processing time of products, produced by supply site $j \in$ $G_{S}$, is definitely less than its total processing time capacity $\Gamma_{j}$ when it is opened (i.e., $Z_{j}=1$ ) and prevents any flow and is fully functional in scenario $s \in S$, when it is disrupted or closed. Accordingly, the supply site $j \in$ $G_{S}$ can have some partial disturbances; therefore, it can work with $\left(1-\Xi_{j}^{s}\right) \%$ of the nominal capacity. It is presented as $\Xi_{j}^{s} \in[0,1]$.

$\sum_{p \in P} \sum_{v \in V} \sum_{l \in L} \sum_{(i, j) \in A} \psi^{p} Y_{i j}^{p l v s} \leq\left(1-\Phi_{j}^{s}\right)\left(1-\Xi_{j}^{s}\right) \Theta_{j}^{p} Z_{j}$
$\forall j \in G_{T}, \quad s \in S$.

Constraints (9) guarantee that the summation of weights of the flow of products, transported by $\mathrm{DC} j \in G_{\mathrm{T}}$, is definitely less than its capacity $\Theta_{j}$, when it is opened (i.e., $Z_{j}=1$ ), and prevents any flow and is fully functional in scenario $s \in S$, when it is disrupted or closed. Also, the distribution center $j \in G_{S}$ can have some partial disturbances; therefore, it can work with $\left(1-\Xi_{j}^{s}\right) \%$ of the nominal capacity. It is presented as $\Xi_{j}^{s} \in[0,1]$.

$$
\begin{aligned}
& \sum_{p \in P} \sum_{v \in V} \sum_{l \in L} \Theta_{j}^{p} Y_{i j}^{p l v} \leq\left[\left(1-\Omega_{i j}^{s}\right)\left(1-\mho_{i j}^{s}\right) \sum_{l \in L} \Pi_{i j}^{l}\left(X_{i j}^{l}+X_{j i}^{l}\right)\right] \\
& \forall s \in S, \quad(i, j) \in A .
\end{aligned}
$$

Constraints (10) emphasize that the total flow through the link $(i, j) \in A$ does not overstep its capacity $\Pi_{i j}^{l}$, when it is constructed (i.e., $X_{i j}^{l}+X_{j i}^{l}=1$ ) and any flow prevented, and is fully functional in scenario $s \in S$ when it is disrupted or closed. Also, the link $(i, j) \in A$ can have some partial disturbances (e.g., bad weather conditions, avalanche, earthquake, etc.); therefore, it can used with $\left(1-\mho_{i j}^{s}\right) \%$ of the nominal capacity; i.e., its capacity is reduced to $\left(\mho_{i j}^{s}\right) \%$. It is presented as $\mho_{i j}^{s} \in[0,1]$. 
$\sum_{p \in P} \psi^{p} Y_{i j}^{p l v s} \leq\left[\left(1-\Delta_{i j}^{l v s}\right)\left(1-\coprod_{i j}^{l v s}\right) W_{i j}^{v} \lambda_{i j}^{v}\right] \quad \forall(i, j) \in A$,

$s \in S, \quad v \in V, \quad l \in L$.

Constraints (11) guarantee that the summation of weights of the flow, transported by vehicle $v$ through the link $(i, j) \in A$ with type $l$, does not exceed its capacity $\lambda_{i j}^{v}$ when it is established (i.e., $W_{i j}^{v}=1$ ) and any flow prevented, and is fully functional in scenario $s \in S$, when it is disrupted or closed. Similarly, also, the vehicle $(i, j)$ $v \in V$ can have some partial disturbances and can work with $\left(1-\coprod_{i j}^{l v s}\right) \%$ of the nominal capacity. It is presented as $\coprod_{i j}^{l v s} \in[0,1]$.

$\sum_{l \in L}\left(X_{i j}^{l}+X_{j i}^{l}\right) \leq 1 \quad \forall(i, j) \in A$.

Constraints (12) prevent links from being opened in both directions with several quality types at once.

$\sum_{v \in V} W_{i j}^{v} \leq U_{i j}^{\max } \quad \forall(i, j) \in A$.

Constraints (13) restrict the maximum number of vehicle type that may be used through the link $(i, j) \in A$.

$W_{i j}^{v} \leq \sum_{l \in L}\left(X_{i j}^{l}+X_{j i}^{l}\right) \quad \forall v \in V, \quad(i, j) \in A$.

Constraints (14) guarantee that the vehicle establishing at link $(i, j) \in A$ can be happed when the link, with at least one of the quality type, is opened.

$Z_{j} \in\{0,1\} \quad \forall j \in G_{0}$,

$W_{i j}^{v} \in\{0,1\} \quad \forall v \in V, \quad(i, j) \in A$,

$X_{i j}^{l} \in\{0,1\} \quad \forall l \in L, \quad(i, j) \in A$,

$\delta_{j} \in\{0,1\} \quad \forall j \in G_{0}$,

$Y_{i j}^{p l v s} \geq 0 \quad \forall(i, j) \in A, \quad p \in P, \quad v \in V, \quad l \in L, \quad s \in S$.

Constraints (15)-(18) declare the binary variables and, finally, constraints (19) guarantee that the variable $Y_{i j}^{p l v s}$ will be non-negative.

\section{Reliable counterpart stage 2 (for each reliable scenario)}

The reliable counterpart stage 2 of $\mathrm{RR} / \mathrm{CMc} / \mathrm{SCNDP}_{\mathrm{s}}$, as a model (II), can be presented as follows:

Model (II):

$$
\begin{aligned}
\min \xi_{s}= & \sum_{j \in G_{0}} f_{j} Z_{j}+\sum_{l \in L} \sum_{(i, j) \in A} c_{i j}^{l} X_{i j}^{l}+\sum_{v \in V} \sum_{(i, j) \in A} \gamma_{i j}^{v} W_{i j}^{v} \\
& +\sum_{p \in P} \sum_{v \in V} \sum_{l \in L} \sum_{(i, j) \in A} t_{i j}^{p l v} \cdot \pi_{s} Y_{i j}^{p l v s}
\end{aligned}
$$

$$
\begin{aligned}
& \text { s.t. } \sum_{v \in V} \sum_{l \in L} \sum_{(j, i) \in A} Y_{i j}^{p l v s}-\sum_{v \in V} \sum_{l \in L} \sum_{(j, i) \in A} Y_{j i}^{p l v s}+d_{j}^{p} \leq\left(1-\Xi_{j}^{s}\right) \Theta_{j}^{p} \\
& +M \Phi_{j}^{s}+M\left(1-z_{j}\right) \quad \forall j \in G_{0}, \quad p \in P,
\end{aligned}
$$

$\sum_{v \in V} \sum_{l \in L} \sum_{(j, i) \in A} Y_{j i}^{p l v s}-\sum_{v \in V} \sum_{l \in L} \sum_{(j, i) \in A} Y_{i j}^{p l v s} \leq d_{j}^{p}+M \delta_{j}$

$$
\forall j \in G_{0}, \quad p \in P,
$$

$\sum_{v \in V} \sum_{l \in L} \sum_{(j, i) \in A} Y_{j i}^{p l v s}-\sum_{v \in V} \sum_{l \in L} \sum_{(j, i) \in A} Y_{i j}^{p l v s} \geq d_{j}^{p}+M\left(1-\delta_{j}\right)$ $\forall j \in G_{\mathrm{D}}, \quad p \in P$,

$\delta_{j}+\left(1-\Phi_{j}^{s}\right) z_{j}=1 \quad \forall j \in G, \quad s \in S$,

$\sum_{p \in P} \sum_{v \in V} \sum_{l \in L} \sum_{(i, j) \in A} \varphi_{j}^{p} Y_{i j}^{p l v s} \leq\left(1-\Phi_{j}^{s}\right)\left(1-\Xi_{j}^{s}\right) \Gamma_{j} Z_{j}$

$\forall j \in G_{S}$,

$\sum_{p \in P} \sum_{v \in V} \sum_{l \in L} \sum_{(i, j) \in A} \psi^{p} Y_{i j}^{p l v s} \leq\left(1-\Phi_{j}^{s}\right)\left(1-\Xi_{j}^{s}\right) \Theta_{j}^{p} Z_{j}$
$\forall j \in G_{T}$,

$$
\begin{aligned}
& \sum_{p \in P} \sum_{v \in V} \sum_{l \in L} \Theta_{j}^{p} Y_{i j}^{p l v s} \leq\left[\left(1-\Omega_{i j}^{s}\right)\left(1-\mho_{i j}^{s}\right) \sum_{l \in L} \Pi_{i j}^{l}\left(X_{i j}^{l}+X_{j i}^{l}\right)\right] \\
& \forall(i, j) \in A,
\end{aligned}
$$

$\sum_{p \in P} \psi^{p} Y_{i j}^{p l v s} \leq\left[\left(1-\Delta_{i j}^{l v s}\right)\left(1-\coprod_{i j}^{l v s}\right) W_{i j}^{v} \lambda_{i j}^{v}\right] \quad \forall(i, j) \in A$, $v \in V, \quad l \in L$,

$Y_{i j}^{p l v s} \geq 0 \quad \forall(i, j) \in A, \quad p \in P, \quad l \in L, \quad v \in V$,

and constraints (8) and (12-18).

\section{Solution approach}

\section{A hint}

Basically, most of the SCs and logistic systems can be affected from two broad categories of risk. The first category is a 
parameter (e.g., demand, fixed prices, operational prices, lead times) uncertainty and the second category is system disturbances (e.g., economic disturbances, strikes, natural disasters, and terrorist attacks). One of the most efficient approaches to deal with the first category is robust optimization (RO). Since the late 1990s, this approach has been applied broadly in the area of uncertain control and optimization. Several RO approaches are presented in the literature review (e.g., Mulvey et al. 1995; Ben-Tal and Nemirovski 1998, 1999, 2000; Yu and Li 2000), (Bertsimas and Sim 2003, 2004; Leung et al. 2007), (Bozorgi-Amiri et al. 2011; Pishvaee et al. 2011; Shishebori and Babadi 2015). According to the efficient beneficial properties of the Pishvaee et al. (2011) approach for our problem, in this study, this robust approach is considered which is conducive to cope with the related parameter uncertainty. For more detailed reading about this robust optimization approach, we refer researchers to Pishvaee et al. (2011).

In the following, the application of the mentioned robust approach for our problem is represented.

\section{Robust reliable counterpart stage 1}

Due to previous explanations, the robust counterpart of the suggested market to market closed-loop SC network (Model (III) for the RR/CMc/SCNDP and Model (IV) for the $\mathrm{RR} / \mathrm{CMc} / \mathrm{SCNDP}_{\mathrm{s}}$ ) design problem with stochastic demands, transportation costs specified by box sets are equipollent to the following MIPs:

Model (III):

$\min \quad \operatorname{RETC}=\exists$,

$\left[\begin{array}{c}\sum_{j \in G_{0}} f_{j} Z_{j}+\sum_{l \in L} \sum_{(i, j) \in A} c_{i j}^{l} X_{i j}^{l}+\sum_{v \in V} \sum_{(i, j) \in A} \gamma_{i j}^{v} W_{i j}^{v} \\ +\sum_{p \in P} \sum_{l \in L} \sum_{v \in V} \sum_{(i, j) \in A}\left(\bar{t}_{i j}^{p l v} \cdot \pi_{0} Y_{i j}^{p l v 0}+{ }^{t} \eta_{i j}^{p l v 0}\right)\end{array}\right] \leq \exists$,

s.t.

$\left[\begin{array}{c}\sum_{j \in G_{0}} f_{j} Z_{j}+\sum_{(i, j) \in A} c_{i j}^{l} X_{i j}^{l}+\sum_{v \in V} \sum_{(i, j) \in A} \gamma_{i j}^{v} W_{i j}^{v} \\ +\sum_{p \in P} \sum_{v \in V} \sum_{l \in L} \sum_{(i, j) \in A}\left({ }_{i j}^{p l v} . \pi_{s} Y_{i j}^{p l v s}+{ }^{t} \eta_{i j}^{p l v s}\right)\end{array}\right] \leq\left(1-P_{R}\right) \xi_{s}^{*}$ $\forall s \in S /\{0\}$,

$$
\begin{aligned}
& {\left[\begin{array}{l}
\sum_{v \in V} \sum_{l \in L} \sum_{(j, i) \in A} Y_{i j}^{p l v s}-\sum_{v \in V} \sum_{l \in L} \sum_{(j, i) \in A} Y_{j i}^{p l v s} \\
\quad+\bar{d}_{j}^{p}-\rho_{d} G_{d j}^{p}
\end{array}\right] \leq\left(1-\Xi_{j}^{s}\right) \Theta_{j}^{p}} \\
& \quad+M \Phi_{j}^{s}+M\left(1-z_{j}\right) \quad, \quad s \in S, \quad p \in P,
\end{aligned}
$$

$$
\begin{aligned}
& \sum_{v \in V} \sum_{l \in L} \sum_{(j, i) \in A} Y_{j i}^{p l v s}-\sum_{v \in V} \sum_{l \in L} \sum_{(j, i) \in A} Y_{i j}^{p l v s} \leq \bar{d}_{j}^{p}-\rho_{d}^{d} G_{j}^{p}+M \delta_{j} \\
& \forall j \in G_{0}, \quad s \in S, \quad p \in P,
\end{aligned}
$$

$$
\begin{aligned}
& \sum_{v \in V} \sum_{l \in L} \sum_{(j, i) \in A} Y_{j i}^{p l v s}-\sum_{v \in V} \sum_{l \in L} \sum_{(j, i) \in A} Y_{i j}^{p l v s} \geq \bar{d}_{j}^{p}+\rho_{d} G_{d j}^{p} \\
& \quad+M\left(1-\delta_{j}\right) \\
& \quad \forall j \in G_{D}, \quad s \in S, \quad p \in P
\end{aligned}
$$

$\sum_{p \in P} \sum_{v \in V} \sum_{l \in L} \sum_{(i, j) \in A}\left(\bar{\varphi}_{j}^{p} Y_{i j}^{p l v s}+\eta_{\varphi i j}^{p l v s}\right) \leq\left(1-\Phi_{j}^{s}\right)\left(1-\Xi_{j}^{s}\right) \Gamma_{j} Z_{j}$
$\forall j \in G_{S}, \quad s \in S$,

and constraints $(6,7)$ and (9-19).

\section{Robust reliable counterpart stage 2 (for each reliable scenario)}

Solving the model (IV) can determine the optimal scenario costs $\left(\xi_{s}^{*}\right)$ for the RR/CMc/SCNDP for each of the scenario $s$ which is presented as follows:

Model (IV):

$\min R \xi_{s}=\Upsilon$,

s.t.

$\left[\begin{array}{c}\sum_{j \in G_{0}} f_{j} Z_{j}+\sum_{l \in L} \sum_{(i, j) \in A} c_{i j}^{l} X_{i j}^{l}+\sum_{v \in V} \sum_{(i, j) \in A} \gamma_{i j}^{v} W_{i j}^{v} \\ +\sum_{p \in P} \sum_{l \in L} \sum_{v \in V} \sum_{(i, j) \in A}\left({ }^{p l v}{ }_{i j}^{l v} \cdot \pi_{s} Y_{i j}^{p l v s}+{ }^{t} \eta_{i j}^{p l v s}\right)\end{array}\right] \leq \Upsilon$,

$\rho_{t} G_{t i j}^{p l v s} \leq \eta_{t i j}^{p l v s} \quad \forall(i, j) \in A, \quad p \in P, \quad l \in L, \quad v \in V$,

$\rho_{t} G_{t i j}^{p l v s} \geq-\eta_{t i j}^{p l v s} \quad \forall(i, j) \in A, \quad p \in P, \quad l \in L, \quad v \in V$,

$\left[\begin{array}{l}\sum_{v \in V} \sum_{l \in L} \sum_{(j, i) \in A} Y_{i j}^{p l v s}-\sum_{v \in V} \sum_{l \in L} \sum_{(j, i) \in A} Y_{j i}^{p l v s} \\ \quad+\bar{d}_{j}^{p}-\rho_{d} G_{d j}^{p}\end{array}\right] \leq\left(1-\Xi_{j}^{s}\right) \Theta_{j}^{p}$
$\quad+M \Phi_{j}^{s}+M\left(1-z_{j}\right)$
$\quad \forall j \in G_{0}, \quad p \in P$,

$\sum_{v \in V} \sum_{l \in L} \sum_{(j, i) \in A} Y_{j i}^{p l v s}-\sum_{v \in V} \sum_{l \in L} \sum_{(j, i) \in A} Y_{i j}^{p l v s} \leq \bar{d}_{j}^{p}-\rho_{d}^{d} G_{j}^{p}+M \delta_{j}$ $\forall j \in G_{0}, \quad p \in P$, 


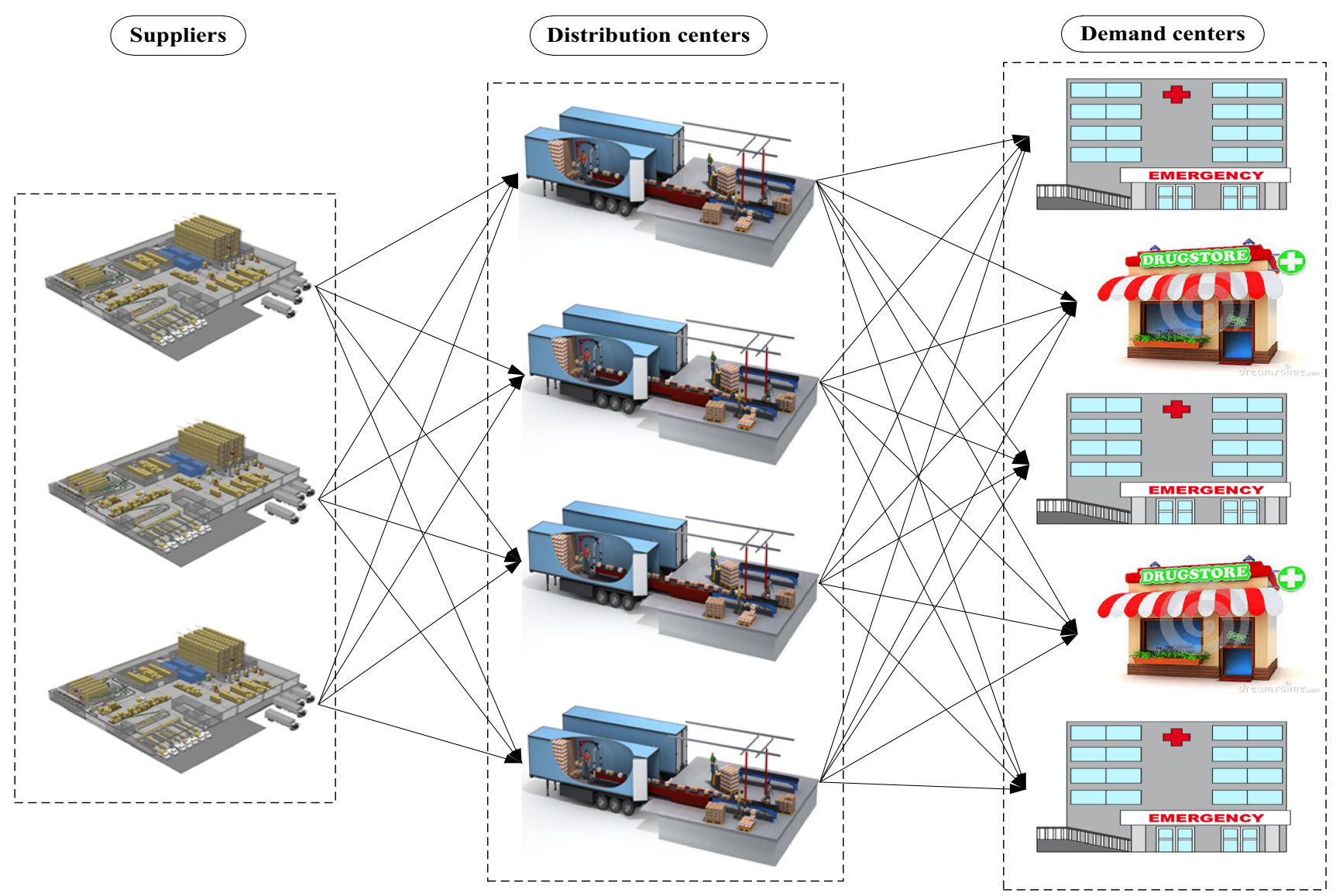

Fig. 1 Generic pattern for SC configuration (e.g., drug SC)

$$
\begin{aligned}
& \sum_{v \in V} \sum_{l \in L} \sum_{(j, i) \in A} Y_{j i}^{p l v s}-\sum_{v \in V} \sum_{l \in L} \sum_{(j, i) \in A} Y_{i j}^{p l v s} \geq \bar{d}_{j}^{p} \\
& \quad+\rho_{d} G_{d j}^{p}+M\left(1-\delta_{j}\right), \quad \forall j \in G_{D}, \quad p \in P \\
& \sum_{p \in P} \sum_{v \in V} \sum_{l \in L} \sum_{(i, j) \in A}\left(\bar{\varphi}_{j}^{p} Y_{i j}^{p l v s}+\eta_{\varphi p i j}^{p l v s}\right) \leq\left(1-\Phi_{j}^{s}\right)\left(1-\Xi_{j}^{s}\right) \Gamma_{j} Z_{j} \\
& \quad \forall j \in G_{S},
\end{aligned}
$$

and constraints (8), (12-18), (24) and (26-29).

\section{Real-life case study}

Here, a real-life case study represents the application of the $\mathrm{RR} / \mathrm{CMc} / \mathrm{SCNDP}$. In this case study, the goal is to access improvement of the urban residence centers (towns) to MS centers. The case is related to one of the biggest drug supply/ distribution chain networks named Daru Pakhsh. This company is one of the biggest drug supply/distribution chain networks in the Middle East and has several essential drugs and also numerous cosmetic accessories. Daru Pakhsh is trying to improve the customer satisfaction index in drug supply/distribution chain network by delivering of demands to customers on time and with also minimum total costs (e.g., drug stores, clinics, and hospitals). According to the degree of the demand emergency, different transportation vehicles, including road transportation (e.g., refrigerated trucks, etc.), rail transportation, and air transportation (e.g., helicopter, etc.), can be used. At this time, there are two supply and eight distribution centers. This company wants to develop the extent of its supply/distribution network in the country via increasing the number of the supply and distribution centers and improving the transportation network.

The case study can be modeled by the RR/CMc/SCNDP as a real practical problem. Considering the security of financial information of the company, this information is not reported here. In the following, other complementary details of the case study are explained; then, the problem is solved and the parameter sensitivity is done (Fig. 1).

Figure 2 presents the existing supply/distribution centers and also potential sites for constructing new facilities (new supply/distribution centers) and new transportation links. As a reminder point, because of better presentation, the demand sites are not shown in Fig. 2; however, all drug stores, clinics, and hospitals in the villages and cities are 


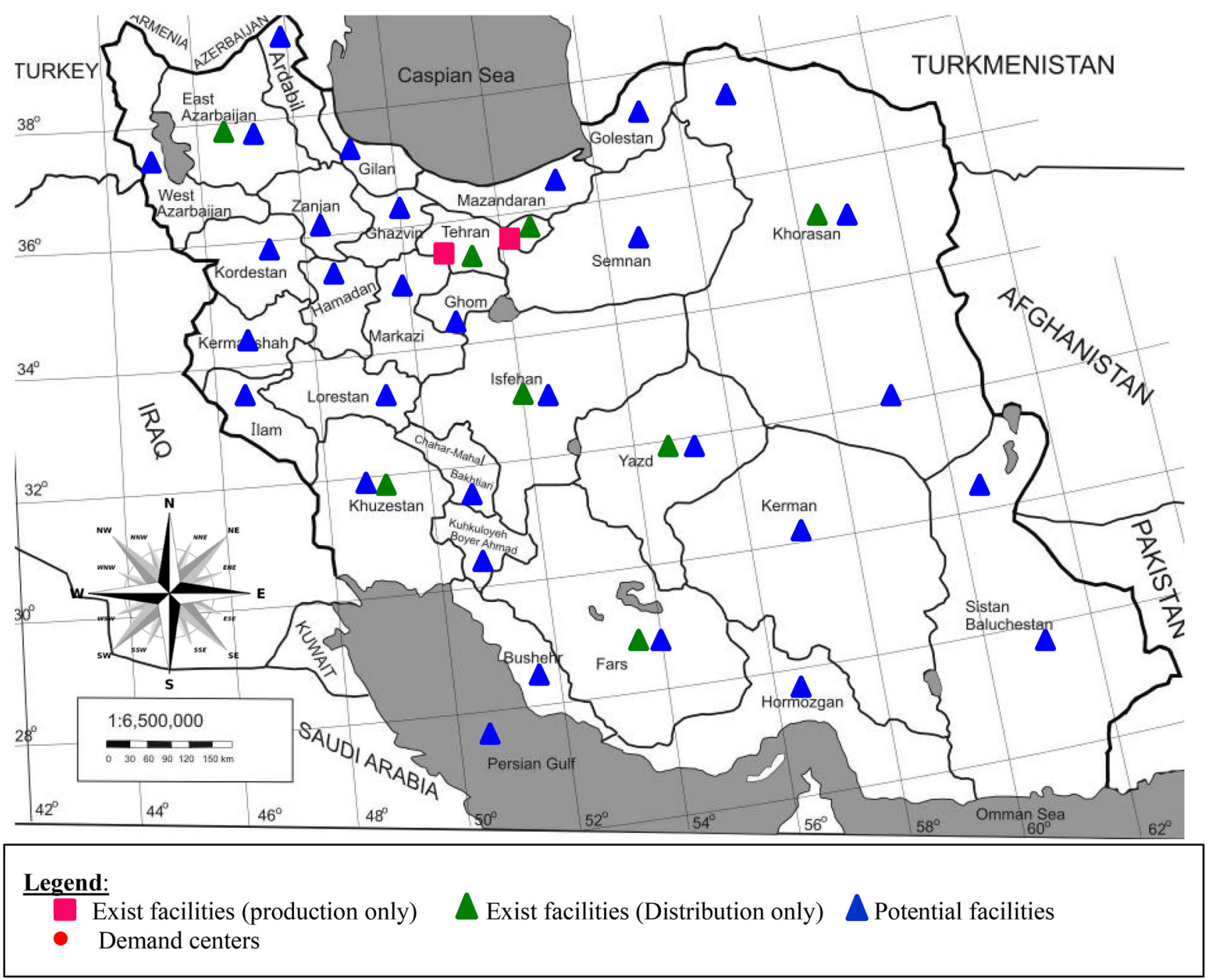

Fig. 2 Existing facilities (including suppliers and distribution centers) and the potential sites for establishing new facilities

the demand sites. The policy of the company is to have a distribution center at each province for easier and faster transportation of the demands of the sites. Moreover, there preferably is a supply center at each region of the country to reduce the transportation costs. Since a supply center can serve as a distribution center too, if a supply center is constructed in a province, then a distribution center will not be constructed there and the supply center will work as a distribution center too. There are three types of road, rail, and air transportation methods.

Due to the aforementioned statuses, it is clear that the mentioned case can be literally considered as an RR/CMc/ SCNDP. As an outcome, the RR/CMc/SCNDP and the RR/ $\mathrm{CMc} / \mathrm{SCNDP}_{\mathrm{s}}$ formulations are adequate mathematical formulations for the case study. The models were coded in the GAMS 24.1 software and executed by CPLEX solver. Figure 3 presents the optimum solution state of the case study.
Figure 3 demonstrates the opening of new facilities at sites shown as green stars. The optimum objective function value is 2,581,423,932 MU (including the optimum value of the fixed cost 41,932,960 MU, and the optimum value of operational cost 2,623,356,892 MU). Likewise, with respect to Fig. 3, it is evident that the provinces Zanjan, Mazandaran, North khorasan, South khorasan, Kermanshah, Kerman, Sistan Balochestan and Abomosa Island are sites that have the minimum location costs; hence, these provinces were selected for locating new facility centers (new distribution centers). Also, new roads (including air, earth and rail lines) are presented in Fig. 3. It is noted that all of the supply/ distribution centers and demand sites are connected via road lines. Therefore, only new applied air and rail lines are presented. All of the demand sites and centers can be connected to each other directly/indirectly via a kind of line (road, air, or rail). 


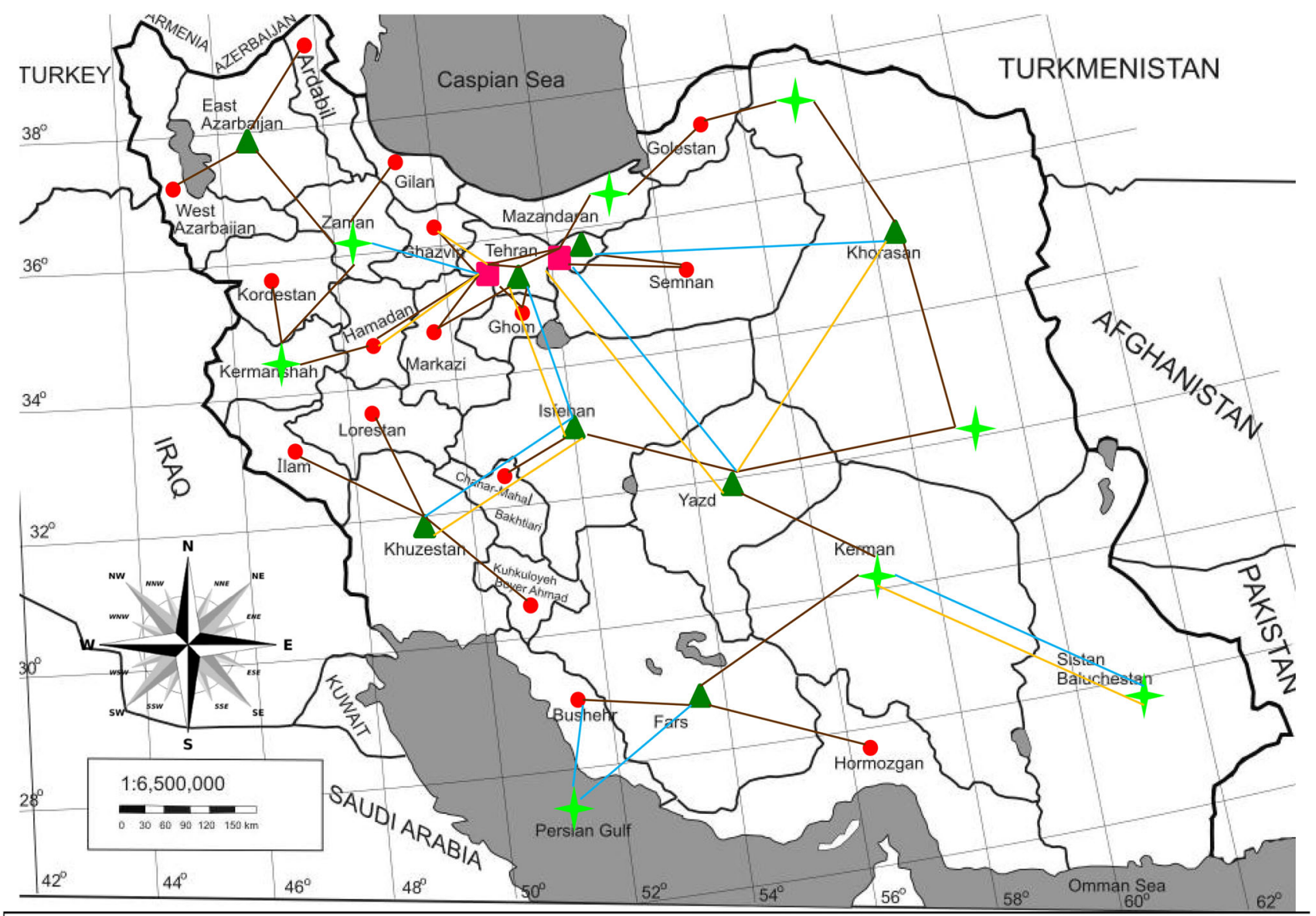

\section{Legend:}

+ New facilities

Air lines

Road lines

Rail lines

Fig. 3 The optimum solution state of the case study

Fig. 4 Changing of the BC regarding fixed and operational costs

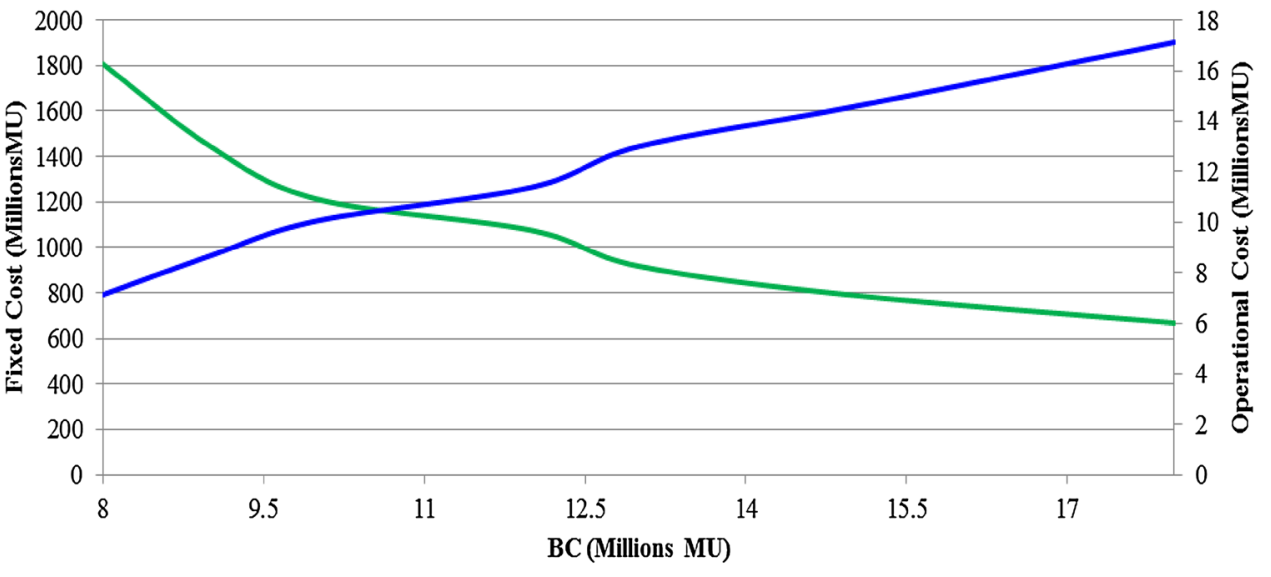

- Operational cost $\quad$ Fixed cost 
Fig. 5 Changing of the BC regarding the objective function value
Table 2 A comparative analysis of general disturbance and fiddling disturbance

Fig. 6 Changing $P_{\mathrm{R}}$ according to the fixed and operational costs

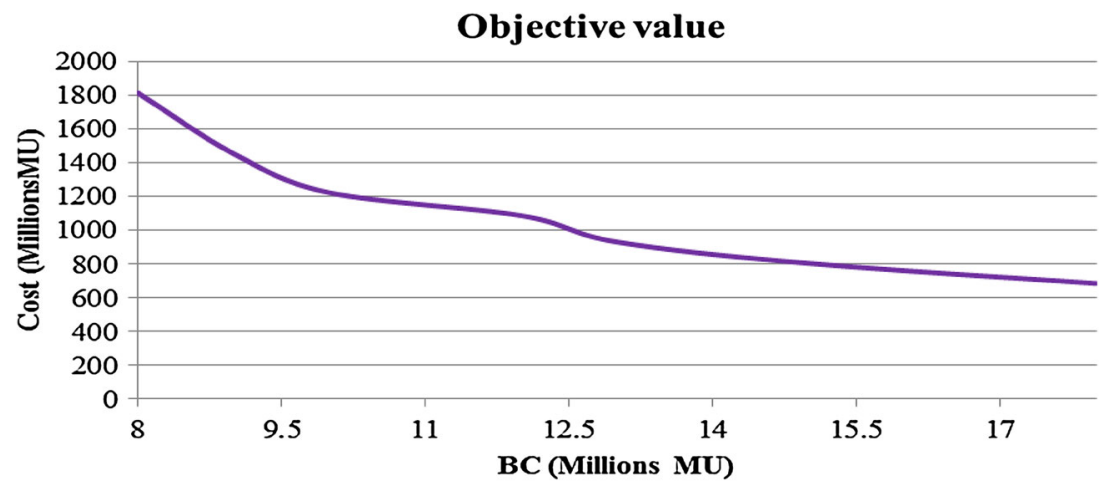

\begin{tabular}{llll}
\hline & Objective value & Fixed costs & Operational costs \\
\hline General disturbance & $3,058,166,039$ & $30,947,927$ & $3,089,113,966$ \\
Fiddling disturbance & $2,581,423,932$ & $41,932,960$ & $2,623,356,892$ \\
\hline
\end{tabular}

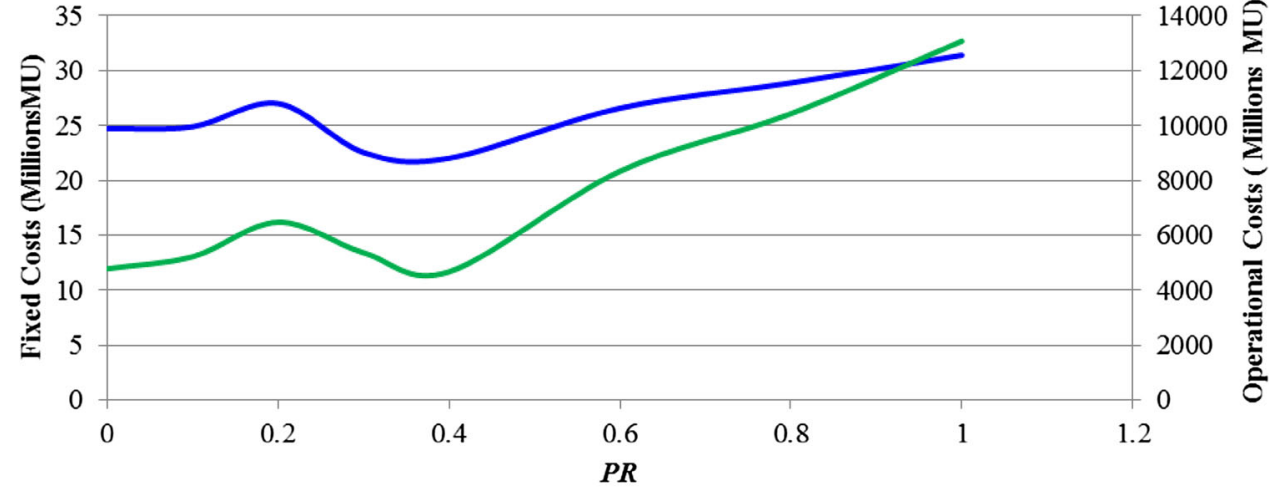

- Fixed costs $\quad$ Operational costs
Table 3 A comparative analysis of changing $P_{\mathrm{R}}$

\begin{tabular}{llrrr}
\hline No. & $P_{\mathrm{R}}$ & Objective value & Fixed costs & Operational costs \\
\hline $\mathrm{TP}_{8}$ & 0 & $4,803,573,965$ & $24,724,118$ & $4,778,849,847$ \\
$\mathrm{TP}_{9}$ & 0.1 & $5,243,131,789$ & $24,894,734$ & $5,218,237,055$ \\
$\mathrm{TP}_{10}$ & 0.2 & $6,499,778,660$ & $27,005,654$ & $6,472,773,005$ \\
$\mathrm{TP}_{11}$ & 0.3 & $5,383,295,009$ & $22,544,225$ & $5,360,750,784$ \\
$\mathrm{TP}_{12}$ & 0.4 & $4,691,692,071$ & $22,028,219$ & $4,669,663,852$ \\
$\mathrm{TP}_{13}$ & 0.6 & $8,363,086,205$ & $26,583,794$ & $8,336,502,411$ \\
$\mathrm{TP}_{14}$ & 0.8 & $10,458,346,768$ & $28,885,271$ & $10,429,461,496$ \\
$\mathrm{TP}_{15}$ & 1 & $13,107,819,927$ & $31,399,030$ & $13,076,420,896$ \\
\hline
\end{tabular}

\section{Sensitivity analysis}

\section{Changes in $\mathrm{BC}$}

Figures 4 and 5 demonstrate that the changing of the investment budget (BC) parameter affects the objective function. It is observed that the fixed costs and the operational costs are increased and decreased, respectively, due to growth of the parameter $\mathrm{BC}$. The reason for this behavior is improved affordability of the new facility location and new link establishment. Accordingly, the operational costs can be considerably reduced. Regarding Fig. 5, it is evident that the total costs, including the fixed costs and operational costs, are reduced due to growth of the parameter BC. Regarding Fig. 4, as a suitable conclusive remark, if the junction of the fixed costs and operational costs is brought up as the optimal value of the BC, then this optimal value can be considered in $[9,500,000$, $11,000,000]$.

\section{Comparing general disturbance and fiddling partial disturbance}

It is noted that the efficiency of the facility with general disturbance is $0 \%$; however, the efficiency of the facility in fiddling partial disturbance is determined as $(1-\lambda) \%$, in 
Fig. 7 Changing of $P_{\mathrm{R}}$ according to the objective value

\section{Objective function}

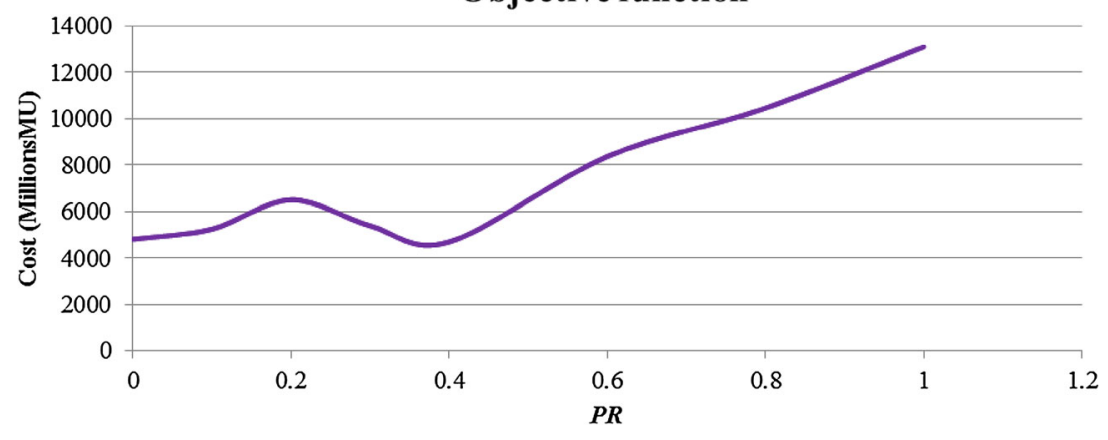

Fig. 8 The sensitivity analysis of changing probability of disturbance by objective value
Fig. 9 The sensitivity analysis of changing probability of disturbance by the objective value
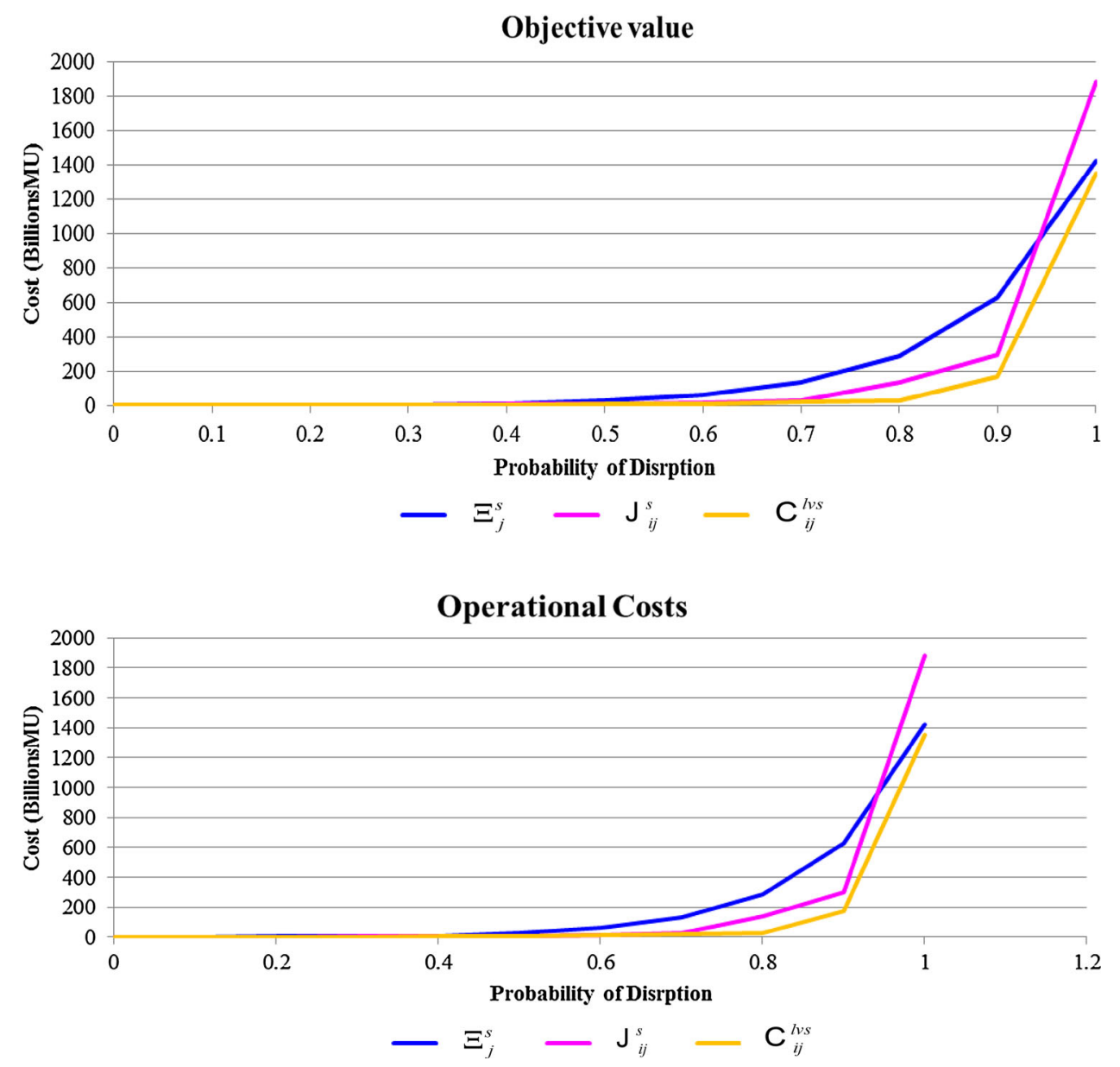

which $\lambda$ is the failure probability. Accordingly, the related comparative analysis of the case study parameters is obtained as Table 2.

Regarding to the Table 2, it is obvious that both of the fixed and operational costs grow with varying of the fiddling partial disturbance to the general disturbance. It is logical; because when a general disturbance happens, the related facility completely fails and cannot service any demand; therefore, extra alternative facilities must be opened conducive to the service of the unmet demands. However, if the fiddling partial disturbance occurs the facility can service with a part of the nominal capacity. Therefore, the growing of the total cost of the fiddling partial disturbance happening is not similar to the growing of the total costs of the general disturbance happening.

\section{Changes of robustness level}

Figure 6 and fourth and fifth columns of Table 3 present the changes of the fixed and operational costs of the objective function vs. the increases of the $P_{\mathrm{R}}$. Also, Fig. 7 and the third column of Table 3 present the changes of the 
Fig. 10 The sensitivity analysis of changing probability of disturbance by the objective value

Fig. 11 The sensitivity analysis of changing $\rho_{d}$ by the objective value

\section{Fixed Costs}

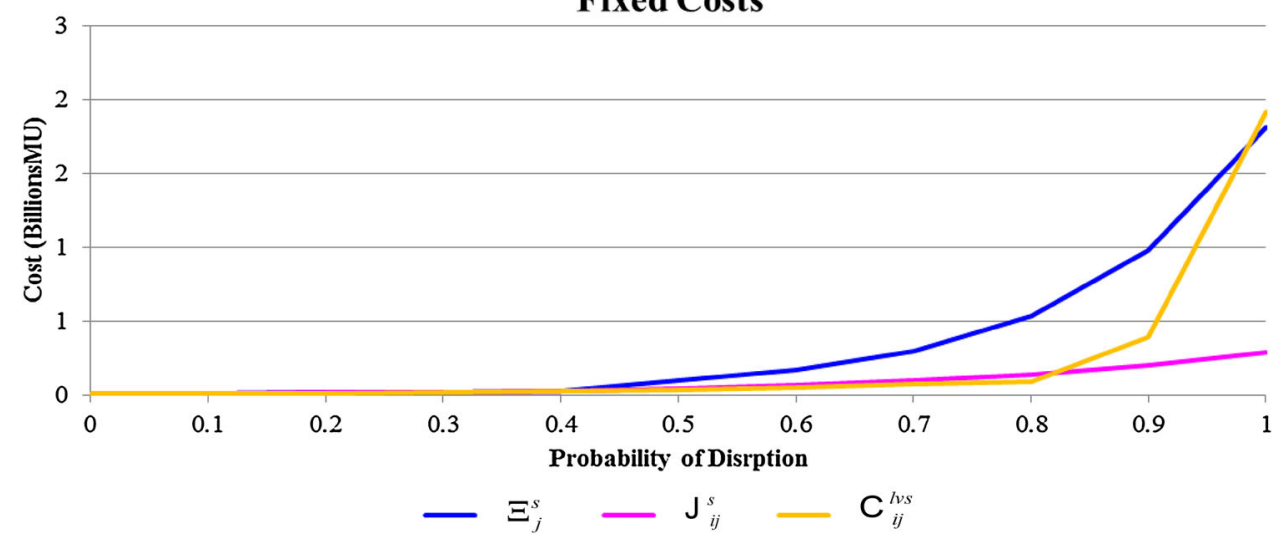

Fig. 12 The sensitivity analysis of changing $\rho_{t}$ by the objective value
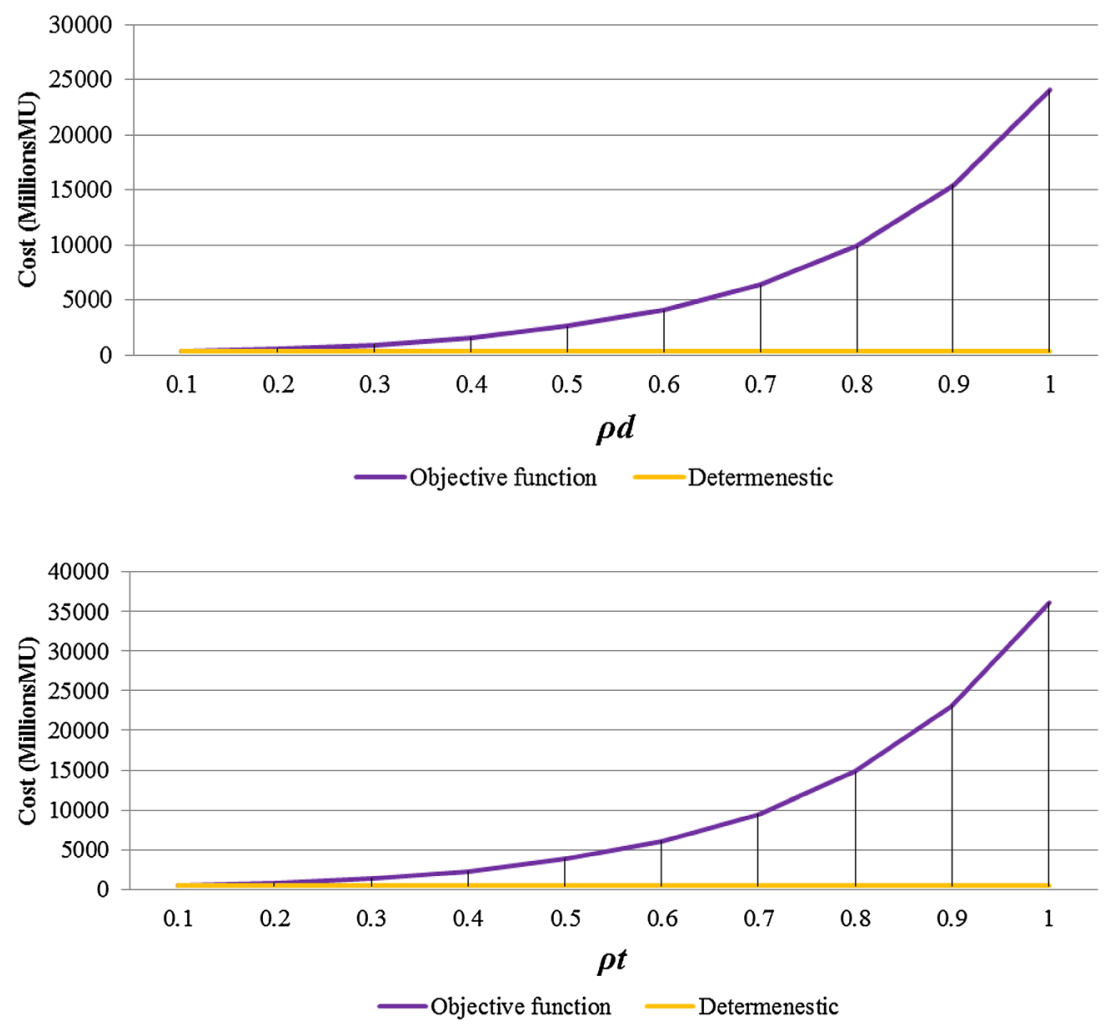

objective function vs. the increases of $P_{\mathrm{R}}$. It can be seen that the right hand side value of the constraint and accordingly the objective value decrease with increase of $P_{\mathrm{R}}$. This decrease event continues to $P_{\mathrm{R}} \approx 0.4$. In the following, the value of objective function considerably increases for $P_{\mathrm{R}}>0.4$. As a concluding remark, it is clear that the best value of $P_{\mathrm{R}}$ can be 0.4 .

\section{Changes of fiddling disturbance parameters $\left(\Xi_{j}^{s}, \mho_{i j}^{s}\right.$, $\left.\coprod_{i j}^{l v s}\right)$}

Figures 8,9 , and 10 present the changing procedure of the fixed costs, operational costs, and total costs regarding the changes of the partial disturbance parameters in facilities $\left(\Xi_{j}^{s}\right)$, links $\left(\mho_{i j}^{s}\right)$, and transportation vehicles $\left(\coprod_{i j}^{l v s}\right)$. It is obvious that the total system costs grow with increase of each of the $\left(\Xi_{j}^{s}\right),\left(\mho_{i j}^{s}\right)$, and $\left(\coprod_{i j}^{l v s}\right)$. As a more comprehensive concluding remarks, when the $\left(\Xi_{j}^{s}\right)$ increases up to $60 \%$, the total costs considerably increase; because the strategic (fixed) costs grow in this state. Moreover, when $\left(\mho_{i j}^{s}\right)$ and $\left(\coprod_{i j}^{l v s}\right)$ increase up to 70 and $80 \%$, respectively, the total costs significantly increase. This analysis emphasizes that the importance of $\left(\Xi_{j}^{s}\right)$ is much more than that of $\left(\mho_{i j}^{s}\right)$ and $\left(\coprod_{i j}^{l v s}\right)$, conducive to ameliorate the reliability and accessibility of the system. 
Furthermore, Figs. 8, 9 and 10 corroborate that the increase of operational costs, regarding to the growing of the $\left(\Xi_{j}^{s}\right)$, is more than this increase, regarding to the growing of the $\left(\mho_{i j}^{s}\right)$ and $\left(\coprod_{i j}^{l v s}\right)$. However, the increase of strategic costs, regarding the growing of the $\left(\coprod_{i j}^{l v s}\right)$, is less than this increase, regarding to the $\left(\mho_{i j}^{s}\right)$.

\section{Changes of the uncertainty level in robust approach $\left(\rho_{t}, \rho_{d}\right)$ and comparison by a certain model}

Figure 11 presents the variable behavior of the total costs regarding the variation of parameter $\rho_{d}$ in the certain and uncertain states of the suggested model. It is observed that the total costs increase when the uncertainty at the value of demand $\left(\rho_{d}\right)$ grows. This motif will be more obvious when the value of uncertainty grows up to $50 \%$. Moreover, Fig. 11 emphasizes that whatever the uncertainty decreases, the total costs at the uncertain state come closer to the total costs at certain states. On the other hand, whatever the uncertainty increases, the gap between the total costs of the uncertain state and the total costs of the certain state will amplify.

Figure 12 presents the changes of the total costs with respect to the variation of parameter $\rho_{d}$ in the certain and uncertain states of the proposed formulation. It is evident that the total costs flourish when the uncertainty at the value of unit transportation costs $\left(\rho_{d}\right)$ grows. While this uncertainty grows up to $60 \%$, the total costs will be significantly increased. This behavior is related to the considerable growth of the total transportation costs. Moreover, Fig. 12 emphasizes that whatever the increases in the value of uncertainty at transportation costs, the difference in the total costs, in the certain state and uncertain state of transportation cost, will increase.

As another concluding remark, comparing Figs. 11 and 12 , it is clear that the growth of the total system costs, due to the uncertainty of demands, is less than the growth of the total system costs, due to uncertainty of transportation costs.

\section{Conclusion}

This paper investigated the problem of robust and reliable designing of a capacitated SCN, which consists of suppliers, DCs, several transportation vehicles, and demand sites as well as some transportation links. They are potential and it should be decided which potential sites and links should be established. Moreover, the SCN has a multi-configuration structure; i.e., there are multi-product, multi-type link, and multi-vehicle states in the considered SCN. Also, two types of risks were considered: (I) uncertain environment,
(II) system disturbances. It is obvious that modifying this SCN and its related logistics will be very difficult and costly. Therefore, it is important to design a reliable and robust SCN that reaches suitable stability and efficiency under several kinds of risks from the start. A two-stage mathematical formulation was proposed for modeling of the mentioned problem. Also, because of uncertain parameters of the model, an efficacious possibilistic robust optimization approach was applied. To validate the model, a drug SCN was studied and the results of the solution model were described and analyzed. Finally, an extensive sensitivity analysis was done on the critical parameters such as the investment budget, robustness level, probability of disturbance in the facilities (including DCs, vehicles and lines), and uncertainty level. The sensitivity analysis indicates the effect of several changes in the key parameters of the model.

Throughout this study, we dealt with the questions that can be proposed as future research for scholars. First, we considered the possibilistic robust aspect of the presented model; however, other aspects of uncertainties (e.g., several probability distributions, intervals, fuzzy sets ...) can be considered. Second, some solution algorithms can be applied to gain the optimal value of the model in the largescale problem. Third, in this study a scenario-based approach of the system disturbance was applied to consider the reliability. Fourth, the study of other uncertainty consideration approaches, e.g., several probability distributions, are suggested to formulate the considered problem and compare these approach behaviors with each other. Accordingly, the proposed model can be more applicable when the agility and resiliency concept are applied to that.

Open Access This article is distributed under the terms of the Creative Commons Attribution 4.0 International License (http://crea tivecommons.org/licenses/by/4.0/), which permits unrestricted use, distribution, and reproduction in any medium, provided you give appropriate credit to the original author(s) and the source, provide a link to the Creative Commons license, and indicate if changes were made.

\section{References}

Amrani H, Martel A, Zufferey N, Makeeva P (2011) A variable neighborhood search heuristic for the design of multi commodity production-distribution networks with alternative facility configurations. OR Spectr 33:989-1007

Aqlan F, Lam SS (2016) Supply chain optimization under risk and uncertainty: a case study for high-end server manufacturing. Comput Ind Eng 93:78-87

Ashtab S (2016) Mathematical modeling and optimization of threeechelon capacitated supply chain network design. Electronic Theses and Dissertations, Paper 5627

Aydin N, Murat A (2013) A swarm intelligence based sample average approximation algorithm for the capacitated reliable facility location problem. Int J Prod Econ 145(1):173-183 
Ayvaz B, Bolat B (2014) Proposal of a stochastic programming model for reverse logistics network design under uncertainties. Int J Supply Chain Manag 3(3)

Babazadeh R, Razmi J, Pishvaee MS (2016) Sustainable cultivation location optimization of the Jatropha curcas L. under uncertainty: a unified fuzzy data envelopment analysis approach. Measurement 89:252-260

Badri H, Bashiri M, Hejazi TH (2013) Integrated strategic and tactical planning in a supply chain network design with a heuristic solution method. Comput Oper Res 40:1143-1154

Bashiri M, Badri H, Talebi J (2012) A new approach to tactical and strategic planning in production and distribution networks. Appl Math Model 36:1703-1717

Bayati MF, Shishebori D, Shahanaghi K (2013) E-products pricing problem under uncertainty: a geometric programming approach. Int J Oper Res 16(1):68-80

Ben-Tal A, Nemirovski A (1998) Robust convex optimization. Math Oper Res 23:769-805

Ben-Tal A, Nemirovski A (1999) Robust solutions of uncertain linear programs. Oper Res Lett 25:1-13

Ben-Tal A, Nemirovski A (2000) Robust solutions of linear programming problems contaminated with uncertain data. Math Progr 88:411-424

Ben-Tal A, Boaz G, Shimrit S (2009) Robust multi-echelon multiperiod inventory control. Eur J Oper Res 199:922-935

Bertsimas D, Sim M (2003) Robust discrete optimization and network flows. Math Progr 98:49-71

Bertsimas D, Sim M (2004) The price of robustness. Oper Res $52: 35-53$

Birge JR, Louveaux F (2011) Introduction to stochastic programming. Springer Science \& Business Media, Springer, New York

Bozorgi-Amiri A, Jabalameli M, Mirzapour Al-e-Hashem SMJ (2011) A multi-objective robust stochastic programming model for disaster relief logistics under uncertainty. OR Spectr. doi:10. 1007/s00291-011-0268-x

Cardona-Valdes Y, Alvarez A, Pacheco J (2014) Metaheuristic procedure for a bi-objective supply chain design problem with uncertainty. Transp Res Part B: Methodol 60:66-84

Chen C-L, Lee W-C (2004) Multi-objective optimization of multiechelon supply chain networks with uncertain product demands and prices. Comput Chem Eng 28:1131-1144

Daskin MS, Snyder LV, Berger RT (2005) Facility location in supply chain design, logistics systems: design and optimization. Springer, New York, pp 39-65

Duan Q, Liao TW (2013) Optimization of replenishment policies for decentralized and centralized capacitated supply chains under various demands. Int J Prod Econ 142:194-204

El-Sayed M, Afia N, El-Kharbotly A (2010) A stochastic model for forwardâ€"reverse logistics network design under risk. Comput Ind Eng 58:423-431

Fattahi M, Mahootchi M, Moattar Husseini SM, Keyvanshokooh E, Alborzi F (2015) Investigating replenishment policies for centralised and decentralised supply chains using stochastic programming approach. Int J Prod Res 53(1):41-69

Ferrio J, Wassick J (2008) Chemical supply chain network optimization. Comput Chem Eng 32:2481-2504

Garcia-Herreros P, Wassick JM, Grossmann IE (2014) Design of resilient supply chains with risk of facility disruptions. Ind Eng Chem Res 53(44):17240-17251

Haldar A, Ray A, Banerjee D, Ghosh S (2014) Resilient supplier selection under a fuzzy environment. Int J Manag Sci Eng Manag 9:147-156

Hatefi SM, Jolai F, Torabi SA, Tavakkoli-Moghaddam R (2015) A credibility-constrained programming for reliable forward-reverse logistics network design under uncertainty and facility disruptions. Int J Comput Integr Manuf 28(6):664-678
Ivanov D, Pavlov A, Sokolov B (2014) Optimal distribution (re) planning in a centralized multi-stage supply network under conditions of the ripple effect and structure dynamics. Eur J Oper Res 237:758-770

Jabalameli MS, Ghaderi A, Shishebori D (2011) An efficient algorithm to solve dynamic budget constrained uncapacitated facility location-network design problem. Int J Bus Manag Stud 3(1):263-273

Jabbarzadeh A, Jalali Naini SG, Davoudpour H, Azad N (2012) Designing a supply chain network under the risk of disruptions. Math Probl Eng. doi:10.1155/2012/234324

Jamshidi R, Fatemi Ghomi SMT, Karimi B (2012) Multi-objective green supply chain optimization with a new hybrid memetic algorithm using the Taguchi method. Sci Iran 19:1876-1886

Jemai Z, Karaesmen F (2007) Decentralized inventory control in a two-stage capacitated supply chain. IIE Trans 39:501-512

Jindal A, Sanggwan KS, Saxena S (2015) Network design and optimization for multi-product, multi-time, multiechelon closed-loop supply chain under uncertainty. Procedia CIRP 29:656-661

Jung JY, Blau G, Pekny JF, Reklaitis GV, Eversdyk D (2004) A simulation based optimization approach to supply chain management under demand uncertainty. Comput Chem Eng 28(10):2087-2106

Karimi-Nasab M, Shishebori D, Jalali-Naini SGR (2013) Multiobjective optimisation for pricing and distribution in a supply chain with stochastic demands. Int J Ind Syst Eng 13(1):56-72

Keyvanshokooh E, Fattahi M, Seyed-Hosseini SM, TavakkoliMoghaddam R (2013) A dynamic pricing approach for returned products in integrated forward/reverse logistics network design. Appl Math Model 37(24):10182-10202

Keyvanshokooh E, Ryan SM, Kabir E (2016) Hybrid robust and stochastic optimization for closed-loop supply chain network design using accelerated Benders decomposition. Eur J Oper Res 249(1):76-92

Kleindorfer PR, Saad GH (2005) Managing disruption risks in supply chains. Prod Oper Manage 14(1):53-68

Leung SCH, Tsang SOS, Ng WL, Wu Y (2007) A robust optimization model for multi-site production planning problem in an uncertain environment. Eur J Oper Res 181:224-238

Mahajan J, Radas S, Vakharia AJ (2002) Channel strategies and stocking policies in uncapacitated and capacitated supply chains*. Decis Sci 33:191-222

Meixell MJ, Gargeya VB (2005) Global supply chain design: a literature review and critique. Transp Res Part E Log Transp Rev 41:531-550

Mirzapour Al-E-Hashem SMJ, Malekly H, Aryanezhad MB (2011) A multi-objective robust optimization model for multi-product multi-site aggregate production planning in a supply chain under uncertainty. Int J Prod Econ 134:28-42

Nepal B, Murat A, Babu Chinnam R (2012) The bullwhip effect in capacitated supply chains with consideration for product lifecycle aspects. Int J Prod Econ 136:318-331

Park B, Choi H, Kang M (2007) Integration of production and distribution planning using a genetic algorithm in supply chain management. Anal Des Intell Syst Soft Comput Tech 416-426

Pasandideh SHR, Niaki STA, Asadi K (2015) Bi-objective optimization of a multi-product multi-period three-echelon supply chain problem under uncertain environments: NSGA-II and NRGA. Inf Sci 292:57-74

Peidro D, Mula J, Poler R, Verdegay JL (2009) Fuzzy optimization for supply chain planning under supply, demand and process uncertainties. Fuzzy Sets Syst 160(18):2640-2657

Peng P, Snyder LV, Lim A, Liu Z (2011) Reliable logistics networks design with facility disruptions. Transp Res Part B Methodol 45:1190-1211 
Pishvaee MS, Rabbani M, Torabi SA (2011) A robust optimization approach to closed-loop supply chain network design under uncertainty. Appl Math Model 35(2):637-649

Santoso T, Ahmed S, Goetschalckx M, Shapiro A (2005) A stochastic programming approach for supply chain network design under uncertainty. Eur J Oper Res 167(1):96-115

Sarrafha K, Rahmati SHA, Niaki STA, Zaretalab A (2015) A biobjective integrated procurement, production, and distribution problem of a multi-echelon supply chain network design: a new tuned MOEA. Comput Oper Res 54:35-51

Shishebori D (2014) Study of facility location-network design problem in presence of facility disruptions: a case study (research notE). Int J Eng Trans A Basic 28(1):97

Shishebori D (2016) Reliable multi-product multi-vehicle multi-type link logistics network design: a hybrid heuristic algorithm. J Ind Syst Eng 9(1):92-108

Shishebori D, Babadi AY (2015) Robust and reliable medical services network design under uncertain environment and system disruptions. Transp Res Part E: Log Transp Rev 77:268-288

Shishebori D, Jabalameli MS (2013a) Improving the efficiency of medical services systems: a new integrated mathematical modeling approach. Math Probl Eng 2013:649397-1-64939713. doi:10.1155/2013/649397

Shishebori D, Jabalameli MS (2013b) A new integrated mathematical model for optimizing facility location and network design policies with facility disruptions. Life Sci J 10(1):1896-1906

Shishebori D, Jabalameli MS, Jabbarzadeh A (2013) Facility locationnetwork design problem: reliability and investment budget constraint. J Urban Plan Dev 140(3):04014005

Shishebori D, Snyder LV, Jabalameli MS (2014) A reliable budgetconstrained $\mathrm{fl} / \mathrm{nd}$ problem with unreliable facilities. Netw Sp Econ 14(3-4):549-580

Singh H, Lu R, Bopassa JC, Meredith AL, Stefani E, Toro L (2013) mitoBKCa is encoded by the Kcnmal gene, and a splicing sequence defines its mitochondrial location. Proc Natl Acad Sci 110(26):10836-10841

Sitompul C, Aghezzaf E-H, Dullaert W, Landeghem HV (2008) Safety stock placement problem in capacitated supply chains. Int J Prod Res 46:4709-4727

Snyder LV, Scaparra MP, Daskin MS, Church RL (2006) Planning for disruptions in supply chain networks. Tutorials in operations research: models, methods, and applications for innovative decision making, pp 234-257, ISBN: 13 978-1-877640-20-9

Snyder LV, Atan Z, Peng P, Rong Y, Schmitt AJ, Sinsoysal B (2016) OR/MS models for supply chain disruptions: a review. IIE Trans 48(2):89-109

Song D-P, Dong J-X, Xu J (2014) Integrated inventory management and supplier base reduction in a supply chain with multiple uncertainties. Eur J Oper Res 232:522-536

Taleizadeh AA (2014) An economic order quantity model with partial backordering and advance payments for an evaporating item. Int J Prod Econ 155:185-193

Taleizadeh AA, Nematollahi MR (2014) An inventory control problem for deteriorating items with backordering and financial engineering considerations. Appl Math Model 38:93-109
Taleizadeh AA, Pentico DW (2013) An economic order quantity model with known price increase and partial backordering. Eur J Oper Res 28(3):516-525

Taleizadeh AA, Pentico DW (2014) An economic order quantity model with partial backordering and all-units discount. Int J Prod Econ 155:172-184

Taleizadeh AA, Niaki ST, Aryanezhad MB (2008) Multi-product multi-constraint inventory control systems with stochastic replenishment and discount under fuzzy purchasing price and holding costs. Am J Appl Sci 8(7):1228-1234

Taleizadeh AA, Moghadasi H, Niaki STA, Eftekhari AK (2009) An EOQ-joint replenishment policy to supply expensive imported raw materials with payment in advance. J Appl Sci 8(23):4263-4273

Taleizadeh AA, Niaki STA, Aryanezhad MB (2010a) Replenish-up-to multi chance-constraint inventory control system with stochastic period lengths and total discount under fuzzy purchasing price and holding costs. Int J Syst Sci 41(10):1187-1200

Taleizadeh AA, Niaki STA, Aryanezhad MB, Fallah-Tafti A (2010b) A genetic algorithm to optimize multi-product multi-constraint inventory control systems with stochastic replenishments and discount. Int J Adv Manuf Technol 51(1-4):311-323

Taleizadeh AA, Barzinpour F, Wee HM (2011) Meta-heuristic algorithms to solve the fuzzy single period problem. Math Comput Model 54(5-6):1273-1285

Taleizadeh AA, Niaki STA, Makui A (2012) Multiproduct multiplebuyer single-vendor supply chain problem with stochastic demand, variable lead-time, and multi-chance constraint. Expert Syst Appl 39(5):5338-5348

Taleizadeh AA, Pentico DW, Jabalameli MS, Aryanezhad MB (2013a) An economic order quantity model with multiple partial prepayments and partial backordering. Math Comput Model 57(3-4):311-323

Taleizadeh AA, Wee HM, Jalali-Naini S (2013b) Economic production quantity model with repair failure and limited capacity. Appl Math Model 37(5):2765-2774

Taleizadeh AA, Cardenas-Barron LE, Mohammadi B (2014) Multi product single machine EPQ model with backordering, scraped products, rework and interruption in manufacturing process. Int $\mathbf{J}$ Prod Econ 150:9-27

Toktas-Palut P, Fusun U (2011) Coordination in a two-stage capacitated supply chain with multiple suppliers. Eur J Oper Res 212:43-53

Tsiakis P, Shah N, Pantelides CC (2001) Design of multi-echelon supply chain networks under demand uncertainty. Ind Eng Chem Res 40:3585-3604

You F, Grossmann IE (2008) Design of responsive supply chains under demand uncertainty. Comput Chem Eng 32:3090-3111

Yousefi-Babadi A, Tavakkoli-Moghaddama R, Bozorgi-Amiri A, Seifi S (2017) Designing a reliable multi-objective queuing model of a petrochemical supply chain network under uncertainty: a case study. Comput Chem Eng 100:177-197

Yu C-S, Li H-L (2000) A robust optimization model for stochastic logistic problems. Int J Prod Econ 64:385-397 